\title{
Assessing Three Audiovisual Translated Versions of Toy Story 1: A Functional Approach
}

\author{
Rania Abdel Baky Allam \\ Lecturer, Faculty of Languages, MSA University, Egypt.
}

\begin{abstract}
Audiovisual translation (AVT) is a rather newly explored sub-discipline of translation studies. This paper compares the micro and macro translational strategies adopted in two types of AVT, namely dubbing and fansubbing. The corpus of study is a Disney cartoon, Toy Storyl dubbed from English into two Arabic varieties; Egyptian colloquial Arabic and Modern Standard Arabic (MSA), as well as a fansubbed version translated from English into MSA. The functional approach is realized by employing the points of analysis suggested by Chaume's (2004) model of analyzing audiovisual material and the problematic areas identified by Chiaro (2009), using the micro translational strategies pinpointed by Pedersen's (2005) extralinguistic cultural-bound references (ECRs) analytical model. The results of the research indicate that the fansubbed version tends to adopt a foreignized macro strategy with the direct or literal translation strategy as the prime micro source language (SL) strategy. The Egyptian colloquial Arabic dubbed version tends to adopt a domesticated macro strategy with the substitution strategy as the prime micro target language (TL) strategy. Finally, the MSA dubbed version tends to adopt a foreignized macro strategy with the direct translation strategy as the adopted main micro SL strategy.
\end{abstract}

Keywords: Audiovisual translation; subtitling; dubbing; fansubbing; macro and micro translational strategies; Chaume's AVT codes; Chiaro's problematic areas; Pedersen's ECRs model.

\section{Introduction:}

Audiovisual Translation (AVT) has become a vast area inspiring many researches and can be functional in the development of translation studies. Pérez-González (2014) believes that AVT is a further complicated area with quite a widening scope; an idea confirmed by Denton and Ciampi (2012) who assert that "audiovisual translation is now a well-established sub-discipline of Translation Studies (TS): a position that it has reached over the last twenty years or so" (p. 399).

Khalaf and Rashid (2012) think that AVT has gained such a distinguished position due to the desire to learn more about the peculiarities of other cultures (p. 296). Besides, the idea of intercultural infusion through audiovisual content over the internet is emphasized by Orrego-Carmona (2014, p. 77). 
AVT is quite a unique sub-discipline of TS due to its polysemiotic nature in which it functions on verbal, acoustic and visual levels. It adheres "to the transference of the cultural conceptualization of different SL situations, perhaps by means of verbal and/or non-verbal semiotics" (Thawabteh and Musallam, 2016, p. 109). Thus, it attracts the interest of translation scholars.

\subsection{Research Objectives}

The present study has the following objectives:

- Probing the micro translational strategies adopted in the fansubbed version of the movie under study, according to Pedersen's model (2005).

- Probing the micro translational strategies adopted in the two dubbed versions of the same movie.

- Comparing the micro strategies applied in the three versions with the aim of discovering the macro or mega strategies underlying each type of AVT, concerning the points of analysis suggested in the applied two models of Chaume (2004) and Chiaro (2009).

\subsection{Research Questions}

1. What are the micro and macro translational strategies adopted in the fansubbed and the two dubbed versions of the movie under study?

2. Which of Venuti's (1995) translation strategies, namely domestication and foreignization, is applied in each version of the movie under study?

3. To what extent does the fansubber in his audio visual translated version follow the translational norms adopted in professional subtitling?

4. What are the points of similarity and difference among the three versions of the movie under study?

\section{Review of Literature}

\subsection{Polysemiotic Channels of AVT}

Pérez-González (2009) states that "major meaning-making modes in audiovisual texts include language, image, music, colour and perspective" (p. 13). Therefore, AVT manifests itself in different mediums. Delabastita refers to the channels of AVT including: the verbal auditory or acoustic channel e.g., dialogue, recognizable utterances, background voices and songs, the non-verbal auditory channel, e.g., music and sound effects, the verbal visual channel, e.g. Written signs on the screen and the non-verbal visual channel, e.g., objects in the image (1990, pp. 101-102). 
De Linde and Kay (1999) argue that AVT processes are "influenced by the material structure of a program and the semiotic relations operating between text and image, which must be processed by viewers" (p. 45). Thus, the synchronization of different semiotic elements includes harmony of words of the translation with the pictures, sounds, movements, and overall perspectives. Such synchronization is not restricted to a certain type of AVT.

\subsection{Types of AVT}

Gambier (2009) specifies seven types of AVT. What pertains to the present study is the interlingual type. Among the types of AVT are subtitling, interpreting, free commentary, voice over and subtitling for the deaf and hard of hearing (SDH). However, Bagheri and Nemati (2014) believe that dubbing and subtitling are still two of the most usual ways of presenting a movie to the audience. They are the main focus of this research.

\section{2 .1 Subtitling}

Subtitling is "condensed written translations of original dialogue which appear as lines of text, usually positioned towards the foot of the screen. Subtitles appear and disappear to coincide in time with the corresponding portion of the original dialogue" (Luyken et al., 1991, p. $31)$.

Consequently, Díaz-Cintas (2012) indicates that in subtitling, the target language (TL) visual dialogue is kept one with acoustic source language (SL), thus "subtitlers are expected to opt for solutions that strike the right balance and interaction between all these audio and visual dimensions" (p. 274). Hence, the scope of subtitling extends to the discursive elements that appear in the image (letters, inserts, graffiti, inscriptions, etc.), as well as the information that is contained on the soundtrack (songs, lyrics, voices off).

Zojer (2011) thinks that the big challenge in subtitling lies in projecting lines of text onto a pre-existing canvass of sound and image while being severely restricted by the negotiation of space and time ( $\mathrm{p}$. 399). Accordingly, different semiotic and polysemiotic channels should be taken into good consideration. Besides, spoken features of exclamations, interjections, songs, rhyme, humor, grammar peculiarities should be retained in the subtitles to keep the spontaneous flavor of the spoken word (Matkivska, 2014, p. 41).

\subsubsection{Dubbing}

According to Díaz-Cintas and Anderman, (2009), dubbing is an interlinguistic, acoustic audiovisual type of translation in which the sound track of the SL is changed into a soundtrack of the TL, in an attempt to retain an equivalent audience influence. 
Nornes (1999) believes that the dubbed version of a movie does not retain much of the text's foreign origin, as dubbing involves translation, adaptation, and performance. Thus, as Alkadi (2010) puts it, "content synchrony can be said to be related to a good translation or writing of the script into target language" (p. 51). This makes the dubbed movie nearly a new product. This makes Tveit (2009) think that "authenticity is undeniably sacrificed when a character is deprived of his voice and instead the audience hears the voice of somebody else". (p. 92). However, in Toy Story1, being an animated film, lip synchronization is not that complicated, as the lip movement in cartoon characters are not that observed or experiential.

\subsubsection{Fansubbing}

Eldalees, Al-Adwan and Yahiaoui (2017) define fansubbing as "a relatively new term which is used to refer to subtitles produced by fans or amateur translators of films and TV shows that originate in a country and a language other than their own." (p. 48). Pérez-González (2014) defines this phenomenon, which has started since the nineteen eighties, as an "interventionist practice" by non-professionals (p. 57).

O'Hagan (2009) states that "in the advent of widespread availability of Web 2.0 platforms, fan translation has become a global phenomenon despite its dubious legal status" (p. 49). Their legal status ranges "from deleterious peer-to-peer file sharing to translations and relatively innocuous, socially beneficial fan fiction" (Lee, 2013, p. 197).

Tian (2011) believes that "the fansubbers practise a unique kind of AVT, which is a new and hot field in translation studies" (p. 3). Internet technology helps a lot in ways related to adding subtitles to popular media products. Moreover, Wongseree (2016) indicates that new AVT practices have "led to novel styles of subtitling, including the use of a wide variety of fonts and colours and the collaboration of fans in fansub communities" (p. 60).

Trēde (2016) thinks that fan subtitlers hold the SL material very highly, wishing to maintain all aspects of the original. This is quite opposite to professional subtitlers who alter a lot in the original so as to fit the requirements of the target. Gambier (2009) pinpoints that a fansubbed product is likely to be closer to the original, more word for word, so as to fit for space and time. Thawabteh, and Musallam (2016) affirm that amateur subtitled product quality depends on the understanding of the source material and the competence and expertise of the translator. Thus, the translated product is usually not subject to any translation quality standards. Each fansubber uses his/her own sets of standards. 
According to Nornes (1999), professional subtitling hides the otherness of the original audiovisual product by conforming to the values, language and culture of the target audience. On the contrary, fansubbing, even if considered abusive, preserves the cultural and linguistic flavour of the original. However, this can be either proved or refuted by the findings of the present study.

Bartrina and Espasa (2005) think that "in audiovisual texts there is semiotic interaction between the simultaneous emission of image and text and its repercussions for the translation process" (p. 85). Therefore, the present study analyzes the audiovisual translated material according to all such channels and features, not according to the textual or verbal level only.

\subsection{Translation Strategies}

The AVT, in spite of having a certain medium of translation is subjected also to what can be called translational strategies, norms or rules. Such strategies can be rather generic like macro or mega translation strategies, or specific like micro or minor translation strategies. Throughout different stages of translation studies, such mega strategies have taken many labels. Newmark (1981) puts them as follows: SL emphasis strategies on the one hand: word for word, literal, faithful and semantic translations, and TL emphasis on the other: adaptation, free translation, idiomatic and communicative translations (p. 45).

All such terms nearly revolve around the same two extremes: the translation which is source text (ST) based, and the other which is target text (TT) based. Nida (1964) delineates two extreme approaches in translation, namely formal (the one faithful to the ST) and dynamic (the one leaning towards the TT (ibid, p. 159). Similarly, Catford (1965) introduces the concept of total translation vs. restricted translation. Later, House (1977) introduces the concepts of overt and covert translations. This gives a background for Newmark (1981) to introduce corresponding extremes: semantic and communicative translations.

Since translation is an intercultural activity putting into account levels other than the linguistic one, the dichotomy of literal and liberal language begins to transcend the limits of linguistic level to encompass cultural and other paralinguistic aspects. This is relevant to Venuti's (1995) domestication versus foreignization polarity. "Domestication and foreignization are two basic translation strategies which provide both linguistic and cultural guidance" (Yang 2010, p. 1). Domestication on the one hand is "ethnocentric", which is actualized in getting the foreign ST as close and familiar to the TL values, and thus to the target recipient as possible. On the other hand, foreignization is "ethno deviant", which is manifested in getting the target recipient as close and familiar to the 
source text and to the values and culture of the SL (Venuti, 1995, pp. 1920).

Schuttleworth and Cowie (1997) affirm that domestication entails the interruption of illustrative material, the removal of SL cultural and historical based textual elements and the harmonization of TT with TL preconceptions and preferences. Such steps minimize the strangeness of the foreign text for TL readers (p. 44). The translator's role is creating a TT which is likely to be acceptable in a culture, however quite invisibly. While foreignization, entails usage of a non-fluent, opaque style, freedom from absolute compliance to TL constraints, inclusion of SL cultural and maybe archaic elements spreading the feeling of the governance of the "Other", and thus forcing an alien experience to the TL receptor. Venuti (1995) advocates the idea of retaining the traits of the SL into the TT. An adequate translation is the one which holds the foreignness of the ST without allowing the TL dominants. The TT should signify the difference between the two languages. However, in the present study the focus is on examining the validity of Venuti's conviction, whether the foreignized product would effectively imply the culture and milieu of the "Other", within the fabric of the TL, adequately or not.

Vinay and Darbelnet's (2000) macro translational strategies are the inspiration of the concepts of domestication and foreignization. They put forward the notions of direct or literal translation on the one hand, and that of oblique translation, on the other. Direct (literal) translation entails parallel categories (structural parallelism) and parallel concepts, while oblique translation entails adding elements to the TT with syntactic and lexical changes. The analysis of the macro strategies applied in each version under study, identifying the translation approaches taken by each translator, its steps, entailments and repercussions on the end AVT product is the focus of the present study.

\section{Corpus of Study}

Walt Disney's cartoons are famous all over the world and are translated and shown either in dubbed or subtitled versions in many languages including Arabic, making them quite popular with Arab children (Al-Jabri, 2017, p. 20).

The corpus under study is three audio visual translated versions of Toy story 1. One is fansubbed by an unknown amateur on EgyBest site, while the other two are dubbed in two varieties of Arabic: Egyptian Colloquial Arabic and Modern Standard Arabic (MSA). One is dubbed by Walt Disney with an Egyptian cast, so much addressing Egypt and the rest of the countries familiar with the Egyptian dialect. While the other 
one is dubbed by Jeem TV by a cast from the Levant intended for the whole Arabic speaking countries.

Al-Alami (2006) indicates that "translation through the dubbing process appears to be the most frequently used option in the Arab world regarding children's cartoons" (p. 21). As the Egyptian dialect is considered an understandable variety widely accepted in the Arab world, cartoon producing companies opt for dubbing their movies into Colloquial Arabic to win a large audience. Nevertheless, some companies, such as Disney, opt for translating the movie into MSA to be widely comprehended throughout the Arabic speaking countries in general. They overlook the fact that, due to the long-rooted history of the Egyptian cinema and drama in the Arab world, the Egyptian colloquial Arabic is considered "the lingua franca in the Arab world" (Gamal, 2009, p. 11).

As for the two varieties of Arabic in the present study, they are a stark example of what Ferguson (1959) calls "diglossia". Jabbari (2012) indicates that colloquial Arabic forms "a roughly continuous spectrum of variation" to the extent that "dialects spoken in the eastern and western extremes of the Arab-speaking world being mutually unintelligible" (p. 23). MSA, on the contrary, is a "superposed variety", a reservoir of written creations. It is the variety learned through formal education for most written and formal spoken purposes.

\section{Methodology and Procedures}

The present study is a qualitative, quantitative research. The micro translational strategies adopted in the AVT of the three versions under study are analyzed according to a multi-framed model comprising three analytical models (Chaume's, Chiaro's and Pedersen's). The SL data are retrieved from a PDF file comprising the SL script of Toy Story1. The TL scripts of the fansubbed, Colloquial Arabic and MSA dubbed versions, are transcribed manually from the audiovisual movie script by the researcher.

A functional approach is adopted in selecting the examples highlighting the micro translational strategies. Then a quantitative statistical procedure is taken in an attempt to pinpoint the numerical results yielded from the qualitative analysis of micro strategies. Such statistical results identify the macro or mega strategies underlying the translational decisions opted for in each type of AVT under study. This also helps in revealing the aesthetic, artistic and linguistic traits of each AVT type and focusing on its characteristics (drawbacks or merits), within the highlight of the comparative study. The following chart exhibits the methodological procedures followed in the present study: 


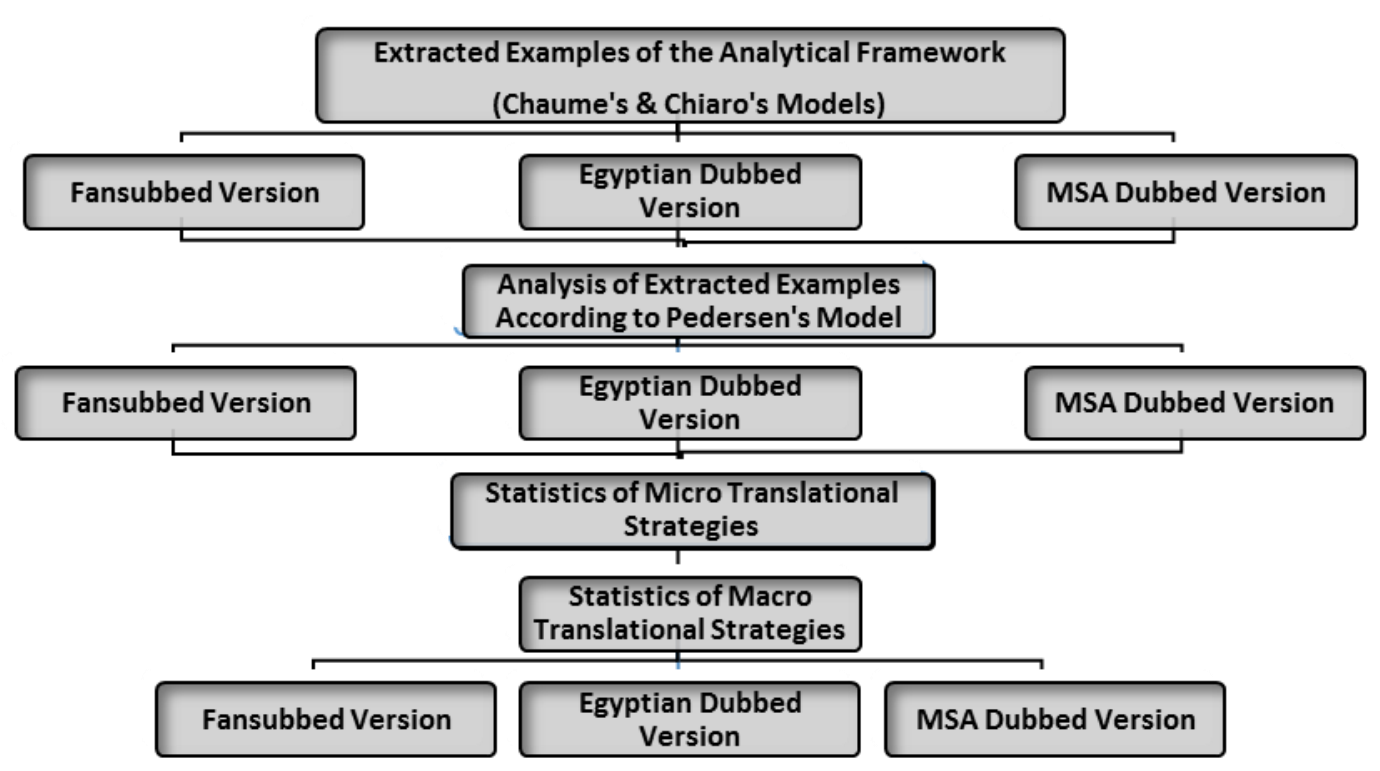

Figure1: Design of Study.

\section{Theoretical Framework}

\subsection{Chaume's Model}

Chaume (2004) proposes a model of analysis that pertains to all the modes involved in the AVT, other than the linguistic textual mode. It is quite appropriate to the subject matter of the present study which compares two versions of a movie dubbed in two varieties of Arabic and fansubbed versions all translated from English into Arabic. The level of analysis entails the visual, acoustic and linguistic levels of the audiovisual translated material. In his model Chaume (2004, pp. 17-22) proposes ten codes of analysis. Six codes only pertain to the present study and can be summarized as follows:

- The linguistic code or text analysis. In this light, it is a written text that has to appear oral and spontaneous as well as the problematic cultural, idiomatic, syntactic, semantic, lexical, discourse areas of translation.

- $\quad$ The musical code which has to do with the songs and lyrics that appear in films that usually require an adaptation in the translation that matches the rhythm number of syllables and tones, and how all of this is presented linguistically.

- The sound arrangement code which is transmitted by the acoustic channel with a direct impact on the translator's task, like sound effects, on and off screen, which also entail (lip synchrony and isochrony) posing constrains for the translation problems posed by the ST. 
The iconographic code which is transmitted via the visual channel representing icons, indices, and symbols in the translation and their linguistic representation.

- $\quad$ The mobility code such as: proxemic signs (the distance of the characters to each other or from the camera), kinetic signs (the movements of the characters on screen) and the screen characters' mouth articulation (the opening and closing of the mouths of the characters in dubbing and the presence of a subtitle on the screen coinciding with the original dialogue in subtitling).

- $\quad$ The syntactic code (editing) which employs syntax to solve problems of excessive length of the translation or problems of isochrony by the use of a pronoun, a synonym or an ellipsis in the translated text.

\subsection{Chiaro's Model}

Chiaro (2009) proposes another model to analyze AVT material. Such model is also based on the concept of polysemiotic levels of analysis. She states that "screen translation is concerned mainly with conveying the verbal audio codes of an audiovisual product into other languages" (p. 142). Therefore, the analysis of the AVT of such product should be actualized on those levels.

Chiaro also states that the translation of each type of AVT mode has its own specific problems as synchronization of lip movement in dubbing and condensation of dialogue to fit into short captions in subtitling. However, both translation types of audiovisual product, either dubbing or subtitling, encounter three primary categories of impediments which he calls "translational hurdles" (p. 155). If such impediments are not tactfully rendered by the audiovisual translator, translational discrepancies can be visually detected by the audiences, i.e. being able to match what they see on screen with what they hear or read. The three levels of obstacles can form a detailed model of analysis, namely:

"1. Highly culture-specific references (CSRs) (entities typical of one particular culture, e.g. place names, references to sports and festivities, famous people, monetary systems, institutions, etc.);

2. Language-specific features (terms of address, taboo language, etc.);

3. Areas of overlap between language and culture (songs, rhymes, jokes, etc.)". (ibid, p. 154).

The features specified above are problematic in nearly all types of translation. Nevertheless, more specifically in audiovisual products, audiences will be able to match what they see on screen (the visuals) with what they hear in a dub or read in a subtitle. Consequently, translating such features entails certain techniques of manifestation in the TT. Chiaro 
then specifies each level, but the following points are the ones pertinent to the present study:

- CSRs is an area of investigation which may include: institutions, (including judiciary, police, military), educational references, place names, units of measurement, national sports and pastimes, food and drink, holidays and festivities, books, films and TV programs, celebrities and personalities. Lingua-specific features include pragmatic features like: forms of address, names, taboo or swear words, on the one hand and visual verbal versus spoken element, on the other. Fuzzy areas include songs, puns, idioms and humor (verbal and non-verbal), (adapted from Chiaro, 2009, pp. 156-163).

Nevertheless, from the point of view of the author of this study, Chiaro's model lacks a paramount analytical dimension of translational decisions, namely: the lexico-semantic level. Therefore, such analytical dimension is probed among the points of analysis suggested by Chiaro.

The following figure illustrates the multi-model framework of the analytical elements under study in the three audio visual translated movies:

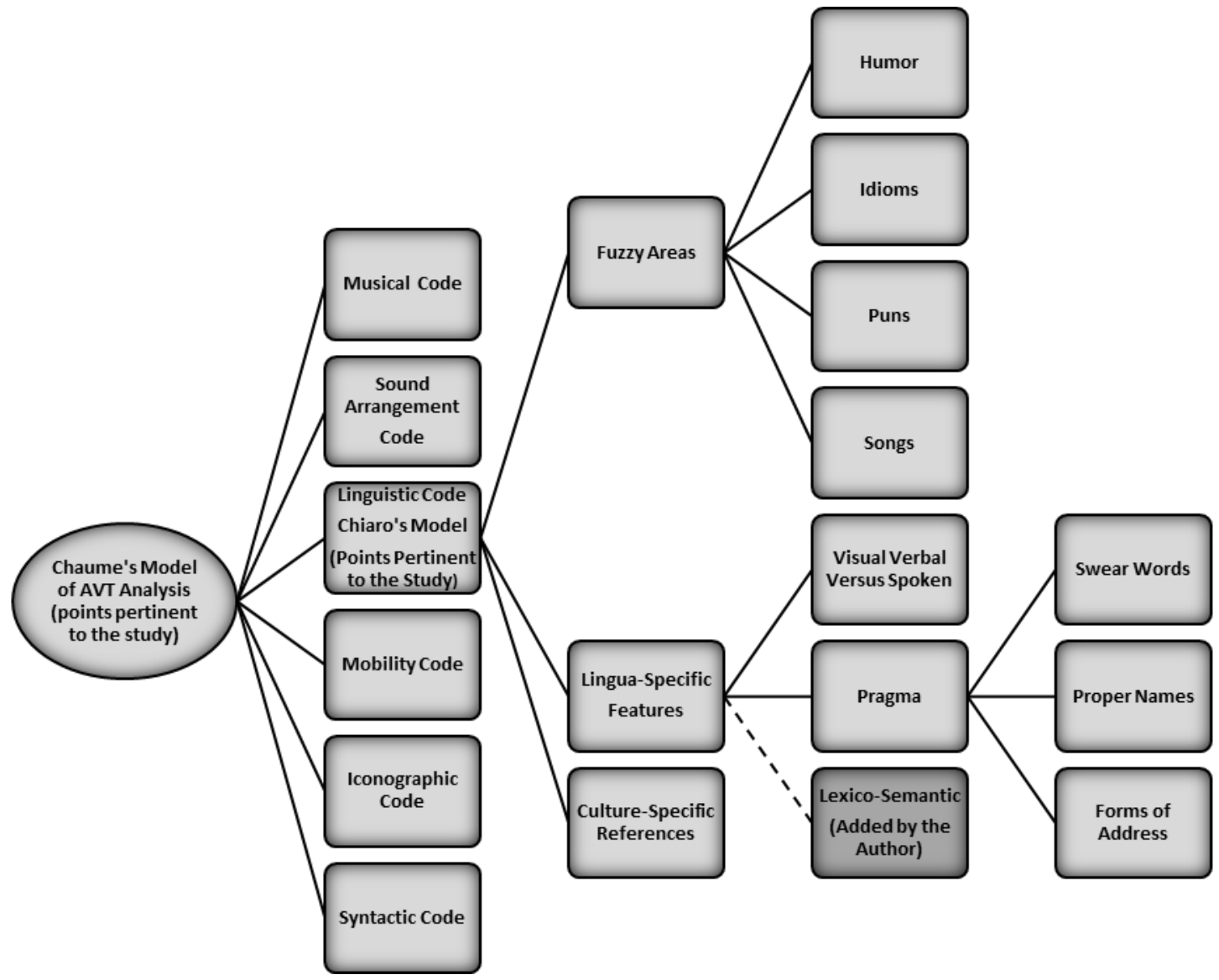

Figure 2: Points of Analysis Adapted from Chaume's (2004) and Chiaro's (2009) Models.

\subsection{Pedersen's Model}




\section{Rania Abdel Baky Allam}

Analyzing the audio visual translation of the above elements pinpointed by Chaume (2004) and Chiaro (2009) is done according to the micro translational strategies suggested by Pedersen (2005) in his model of translating of what he calls "extralinguistic cultural-bound references" (ECRs) (p. 2). This analysis indicates the micro strategies adopted in the three versions, which will lead systematically to the deduction of the macro ones.

Pedersen (2005) states that ECR refers to "an extralinguistic entity or process, and which is assumed to have a discourse referent that is identifiable to a relevant audience as this referent is within the encyclopedic knowledge of this audience" (ibid, p. 2). However, he proposes that his model can be further extended from the bounds of extralinguistic features to encompass "intralinguistic culture-bound references, such as idioms, proverbs, slang and dialects" (cf. p. 2).

Furthermore, in the present study Pedersen's model proves quite efficient as a functional model that can be employed to analyze other intralinguistic features such as the lexico-semantic items, the syntactic dimension, as well as other linguistic features with various functional dimensions such as: forms of anthroponyms (names of people) and toponyms (names of places), puns, taboos and swear words. Besides, he suggests that "it is important to be aware that the translation crisis points only indicate what norms have been operative and then to proceed by analyzing longer stretches of texts, but it gives the analyst a starting point" (ibid, p. 1). He thus suggests some strategies like:

- Official equivalent: in which an official decision by people in authority over an ECR to translate it in a certain way, e.g. Translating 'Donald Duck' as 'Kalle Anka' in Swedish or (Am Batoot in Arabic).

- Retention: in which the ST segment is kept as it is in the TT, not only by spirit, but also by letter.

- Specification: in which the ECR is left as an untranslated form, by adding information not present in the ST, making the TT ECR more specific.

- Explicitation: in which the text is expanded by spelling out anything that is implicit in the ST.

- Addition: in which the translator intervenes to give guidance to the target culture (TC), e.g. Translating Opera Winfrey as أوبرا وينفرى المذيعة المشهورة

- Direct translation: in which the semantic load of the ST ECR is unchanged: nothing is added, or subtracted. 
- Calque: in which the ECR is translated literally, even if it seems odd to the TT audience.

- Shifted: in which obligatory shifts are required by the differences between SL and TL.

- Generalization: in which the translator replaces an ECR referring to something specific by something more general, involving hyponymy, e.g. the name of a particular café has been replaced by a Swedish hyperonym meaning "a café" "the Corinth coffee shopettkafé".

- Substitution: in which the ST ECR is replaced by something else.

- Cultural substitution: in which the ST ECR is replaced by a different ECR known to the TT audience, e.g. Romeo and Juliet in English can be replaced by Hassan we Naaema or Qas and Liala in Arabic.

- Paraphrase: in which the ST ECR is replaced by the TT ECR, either through giving only the meaning or completely removing all trace of the ECR, and, instead, using a paraphrase that fits the context.

- Sense transfer: in which the ST ECR is removed, but its sense or relevant connotations are kept by using a paraphrase, e.g. He celebrated the Halloween with them in English is translated as قل ا حتفل بعبي القديسين معهم

- Situational paraphrase: When using this strategy, every sense of the ST ECR is completely removed, and replaced by something that fits the situation, regardless of the sense of the SC ECR. This strategy could thus be considered a quasi-omission strategy. This method seems to be used a lot when it comes to rendering ECRs in puns.

- Omission: it simply means replacing the ST ECR by nothing. There are circumstances that make Omission the only viable option (adapted from Pedersen, 2005, pp. 3-9) (as some examples are provided by the author).

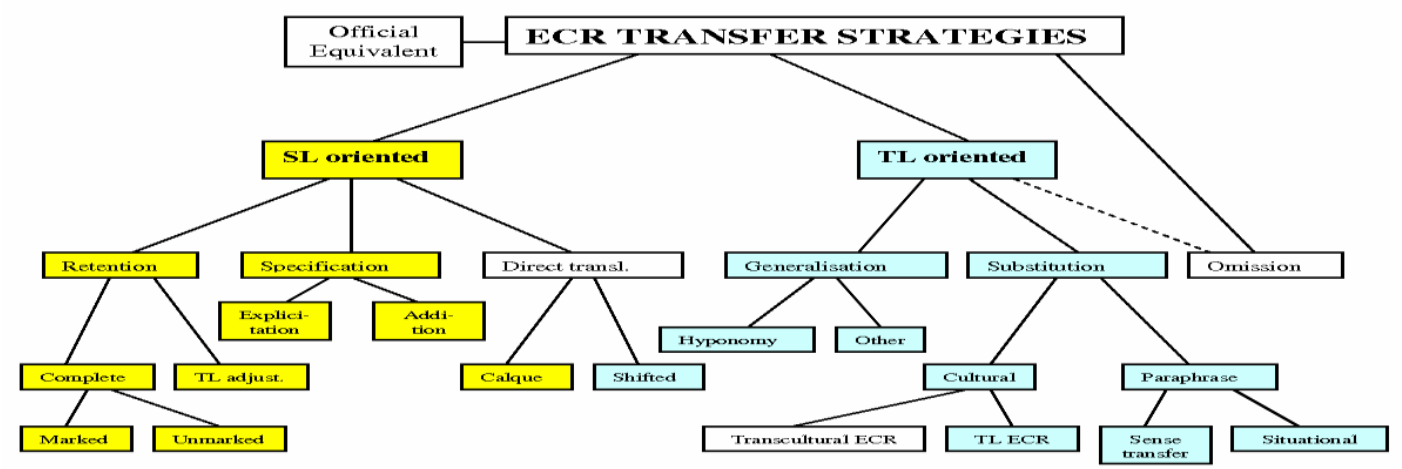


Figure 3: Taxonomy of ECR Transfer Strategies (Pedersen, 2005, p. 4).

\section{Analysis and Discussion}

In this part the study elaborates the analytical process conducted within the framework of Chaume's (2004) model as the overall backbone model of analysis to the three versions under investigation. However, the factors that are deemed significant for this study and whose interaction is quite relevant to the translation process namely: linguistic, musical, sound arrangement, iconographic, mobility and syntactic codes.

\subsection{Musical Code}

Translation of songs as Low (2006) asserts, is a real challenge due to the pre-existing music, with its own rhythms and note-values (p. 512). Accordingly, it is quite apt and dexterous to translate the TL song in a way conveying the plot, character depiction and narrative stream, on the one hand, and preserving the notes, rhythm, and phrasing of the SL song, on the other. A detailed analysis of songs is conducted later in section 6.5.3.1.

\subsection{Sound Arrangement Code}

This type of code is quite palpable in AVT in the dubbed versions under study. It refers to different types of diegetic sounds (i.e. directly coming from the story) and non-diegetic sounds (i.e. coming from a person or an object outside the story), on-screen or off-screen. The two dubbed versions keep the constraints of such code in mind and subtly put across the different sound variations so as to resemble the sound arrangement of the SL version. For instance, the diegetic on-screen sounds such as the play sampled voices of Woody or Buzz coming out of their sound boxes as toys, the electronic sound indicating editing and displaying words on Mr. Spell (the electronic board toy)'s screen, the voices transmitted through the radio monitor, Star Commander's voice coming out of the TV commercial and Woody's voice immitating the voices of Hanna's mum or Buzz are all adroitly communicated in the dubbed versions so as to imply the same implications and denotations in the SL version. As for the diegetic off-screen sounds, they are more proficiently handled in the dubbed Colloquial Arabic version than the fansubbed and the MSA dubbed ones. For instance, the off-screen voices of Andy, his kid guests, as well as his mum in his birthday party are adeptly dubbed as heard from a distance in all versions. However, in the dubbed Colloquial Arabic version the translator opts for conveying a detailed dialogue loaded with culturally adapted distant, off-screen TT segments to be aptly heard by the audience. There is more semantic and lexical load than the fansubbed and the MSA dubbed versions in which the translators suffice to convey an overall condesed meaning of the 
dialogue. The dots (----) in the tables mean that the ST translational segment has no equivelant in this version.

\begin{tabular}{|c|c|c|c|}
\hline ST Dialogue & $\begin{array}{c}\text { Fansubbed } \\
\text { Version }\end{array}$ & $\begin{array}{c}\text { Colloquial } \\
\text { Arabic Dubbed } \\
\text { Version }\end{array}$ & $\begin{array}{l}\text { MSA Dubbed } \\
\text { Version }\end{array}$ \\
\hline $\begin{array}{l}\text { Pizza Deliverer: } \\
\text { Hey, Gas Dude. } \\
\text { Attendent: You } \\
\text { talkin'to me? }\end{array}$ & ----- & ـ لـ سدحت با أسطى. & ـ هرحبا يا عامل \\
\hline $\begin{array}{l}\text { Pizza Deliverer: } \\
\text { Yeah man, can } \\
\text { you help me? Do } \\
\text { you know where } \\
\text { Cutting Blvd. is? }\end{array}$ & ـ هل تعرف أين تقع & ـ كوكب البيتز / منين. & ـ هل تعرف أين تقع الكبنج \\
\hline $\begin{array}{l}\text { Attendent: Just } \\
\text { a moment... } \\
\text { Pizza Deliverer: }\end{array}$ & لحظة... انتظر & ـ ثانية واحلة. & ----- \\
\hline $\begin{array}{l}\text { C'mon, man, } \\
\text { hurry up. Um, } \\
\text { like the pizza's } \\
\text { are getting cold } \\
\text { here. }\end{array}$ & ـ أسرع بارجل البيتزا & ـ يا الله ليا جدع خلصنئ البيترد. & 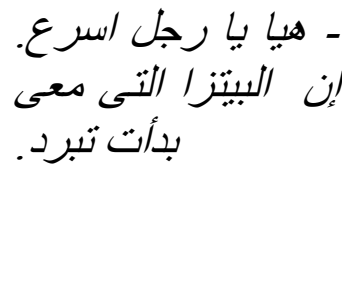 \\
\hline $\begin{array}{l}\text { Pizza Deliverer: } \\
\text { Ok, so that's two } \\
\text { lefts, and then a } \\
\text { right, huh? }\end{array}$ & ----- & ـ ـ آهارع نوبار أبوه & نعم نعم من أبة \\
\hline $\begin{array}{l}\text { Attendent: } \\
\text { Yeah. } \\
\text { Pizza Deliverer: } \\
\text { Okay, thanks for } \\
\text { the directions. }\end{array}$ & ----- & ـ شكرا يا عسل. & شكرا لمعلى على. \\
\hline
\end{tabular}

Table 1: Sample of Sound Arrangement Code.

The off-screen dialogue heard from a distance, between the pizza delivery truck driver and the gas station man, proves a discrepancy in the translation strategies applied in both versions. In the fansubbed version the translator opts for mainly calque, condensation and omission strategies, which resulted in a very abridged dialogue conveying the overall meaning, even-in an abrupt manner. In the Colloquial Arabic dubbed version, the dialogue is mainly translated by finding the unmarked cultural substitution strategy especially in the pragmatic forms of address أسطى، هندسة، جدع، عسل together with the sense transfer 


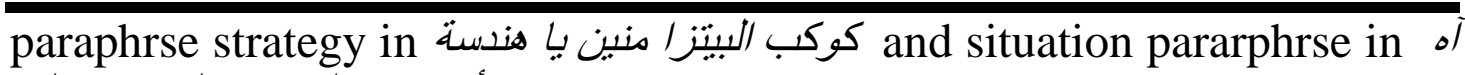
بشارع نوبار أيوه فين قلى - شمال فى شدال

Besides, the translator resorts to the specification by addition strategy to add an authentic flavour to the dialogue. He adds a TT segment which is heared as if from a remote space ما تنساش يبين في بيبن . This segment is not found in the fansubbed or the MSA dubbed version. In the MSA dubbed version the dominant strategy in the whole dialouge is calque with the exception of the sense transfer strategy applied in changing the name of the place in Do you know where Cutting Blvd. is? to هل تعرف أبن تقع جادة الكينج

\subsection{Iconographic Code}

Such code is transmitted via the visual channel representing icons, indices, and symbols. In the original SL version there are some iconic representation transmitted visually, and need to be translated to the TL audience so as to follow the sequence of the plot events. The SL movie displays repeated iconic symbols which are quite visible in different shots to the audience, such as Andy's miniature of western town made of cartoon boxes which have many signs on them representing all the town facilities, a children's illustrated "Wanted" poster of Mr. Potato Head, a cardboard sign taped on the bars of baby Molly's crib with the word "JAIL", Dinoco trademark of a gas station, the sign reading Pizza Planet logo on the delivery shuttle, all the space-themed signs in Pizza Planet restaurant, designed as a space station, and all the games, the sign hanging on Andy's house reading "For Sale" emphasizing the fact that the family is moving to a new house, a radical pivot in the events, the stickers on Buzz; LIGHTYEAR, SPACE RANGER and LAZER, as well as "Made in Taiwan" inscription on his wrist, which later make him realize his toy reality.

All such icons and indices are overlooked in the three audiovisual translated versions. Nonetheless, there is a common trend not to translate such icons as they are not accompanied by verbal dialogue, a fact that overlooks the need of the audience to be aware of what is shown on the screen. The fansubbed version could have easily inscribed the translation of such icons on the screen instantly to synchronize with the visual shot watched by the audience so as to grasp what the symbol or the inscriptions on the signs mean, taking into consideration that in all the shots in which such icons and symbols are displayed, there is enough space for the subtitles to be read by the audience with no interference with the next lines in the dialogue.

Moreover, in the two dubbed versions such dilemma would have been solved by letting the actors, dubbing the voices of the original actors, articulate the translated content of such symbols within the fabric 
of the dubbed dialogue even by compensation strategy, not necessarily in the instant of showing the sign on the screen, taking into advantage the fact that this is an animated movie and the animated characters' lip movement is not that palpable to the audience.

\subsection{Mobility Code}

The proxemic and kinetic signs in the SL movie and the screen characters' mouth articulation exhibit a great deal of translation accuracy in the three versions under investigation. The timing coincidence of the subtitles with the original dialogue in the fansubbed version displays a great deal of proficiency. The phonetic articulation and lip movement of the characters in the two dubbed versions are equally proficient. However, there are some examples of proxemic and kinetic movements which are visually detected on the screen, that need to be elaborated from a translational view point. For instance, Mr. Potato Head draws the sign of the cross by his hand on his chest as a sign of fear and worry, while they are anticipating in panic the new presents brought to Andy on his birthday points. This visually kinetic movement is not exhibited linguistically on any of the AVT versions, maybe as this kinetic sign is quite predictable and universally acquainted. Besides, Bo-Peep moves towards her place by the lamp stand, passing a stack of ABC blocks, saying:

\begin{tabular}{|c|c|c|}
\hline \multicolumn{3}{|c|}{ SL Item: Remember I am just a couple of blocks away. } \\
\hline Fansubbed Version & $\begin{array}{l}\text { Colloquial Arabic } \\
\text { Dubbed Version }\end{array}$ & MSA Dubbed Version \\
\hline $\begin{array}{l}\text { أصاحب اثنان فقط من أنا ـ تذكرج. } \\
\text { Paraphrase by means of } \\
\text { Pituational paraphrasing, } \\
\text { resulting in an exotic, } \\
\text { completely distorted } \\
\text { semantic meaning. }\end{array}$ & $\begin{array}{l}\text { Paraphrase by means of } \\
\text { situational paraphrasing } \\
\text { merged with finding an } \\
\text { unmarked cultural } \\
\text { substitution exemplified } \\
\text { by a part of a famous } \\
\text { song, resulting in an } \\
\text { understandable segment, } \\
\text { semantically and } \\
\text { functionally accepted } \\
\text { and is familiar to the TL } \\
\text { recipient. }\end{array}$ & $\begin{array}{l}\text { - شكر/ لك لأنك /نقت خر/فحى } \\
\text { Paraphrase by means of } \\
\text { situational paraphrasing, } \\
\text { through repeating the } \\
\text { previous translational } \\
\text { segment, while omitting } \\
\text { the ST segment so as to } \\
\text { coincide with the kinetic } \\
\text { movement of Bo-Peep } \\
\text { while looking back to } \\
\text { Woody. This repetition } \\
\text { negatively affects the } \\
\text { semantic load of the ST } \\
\text { and reflects a deficiency } \\
\text { of comprehension on the } \\
\text { part of the translator. }\end{array}$ \\
\hline
\end{tabular}

Table 2: Sample of Mobility Code. 


\section{Rania Abdel Baky Allam}

The pun lies in the fact that there are actually blocks on the floor apparent visually. In ordinary human life, we can hear a couple of blocks meaning two buildings. Nevertheless, each version tackles the ST segment differently.

Furthermore, when Hamm the pig is jumping from a cartoon box over Woody's body aiming at hitting him and causing him pain, as the toys think he is a murderer responsible of many atrocities, he cries out saying "Pig pile". In the fansubbed version it is translated as " الخنزير "قادم". The translation strategy is a specification by addition resulting from kinetic interpretation of the movement done by Hamm, yet conveying a rather inaccurate meaning. In the Colloquial Arabic dubbed version it is translated as "يا خاين" a paraphrase by situation technique, yet coinciding with the kinetic visual movement. In the MSA dubbed version it is translated as " "ضربة قوية" a paraphrase by sense transfer conveying the meaning again coinciding with the kinetic visual movement, yet conveying an evocative equivalent.

\subsection{Linguistic Code}

It has been previously mentioned that the linguistic analysis of the SL audiovisual text is conducted upon the three problematic areas suggested by Chiaro (2009), namely: culture-specific references CSRs, lingua-specific features and fuzzy areas between language and culture, together with the lexico-semantic dimension, suggested in the present study.

Besides, the translational strategies, employed as a basic framework of analysis are those of Pedersen (2005), encompass all the linguistic dimensions under study.

\subsubsection{Cultural Specific Items}

It is one of the primary, problematic and challenging areas of translation, as being specific and limited to a certain culture and pertinently to a certain language. The following examples are demonstrated as a sample of the comparative analysis of culture specific references and their renderings in the three versions:

\section{SL Culture-Specific References CSRs}

1) I've got Cool Ranch and Barbeque. (A food CRS referring to certain flavors of chips).

\begin{tabular}{|c|c|c|}
\hline Fansubbed Version & $\begin{array}{c}\text { Colloquial Arabic } \\
\text { Dubbed Version }\end{array}$ & $\begin{array}{l}\text { MSA Dubbed } \\
\text { Version }\end{array}$ \\
\hline $\begin{array}{l}\text { - أنا عندى مزرعة و حفل شؤ. } \\
\text { A direct calque weird, } \\
\text { peculiar strategy that } \\
\text { does not reflect either }\end{array}$ & $\begin{array}{l}\text { - فيه لحمة باردة و لحمة } \\
\text { A } \quad \text { situational } \\
\text { paraphrase substitution } \\
\text { strategy in which the }\end{array}$ & $\begin{array}{l}\text { - ولدى نكهنان منها - } \\
\text { A generalization by } \\
\text { hyponomy strategy, in } \\
\text { which the MSA dubber } \\
\text { opts for giving a }\end{array}$ \\
\hline
\end{tabular}




\begin{tabular}{|c|c|c|}
\hline $\begin{array}{l}\text { the intended meaning } \\
\text { or any conceivable } \\
\text { meaning in the TL. }\end{array}$ & $\begin{array}{l}\text { dubber alters the } \\
\text { whole SL items } \\
\text { replacing them by a } \\
\text { similar situation and } \\
\text { alternative food stuff, } \\
\text { familiar to the TC, and } \\
\text { the target audience can } \\
\text { expect such type of } \\
\text { sandwiches in birthday } \\
\text { parties. }\end{array}$ & $\begin{array}{l}\text { general meaning of the } \\
\text { flavors without } \\
\text { identifying them. The } \\
\text { meaning is aptly } \\
\text { conveyed in the TL } \\
\text { script in an adequate } \\
\text { and acceptable way. }\end{array}$ \\
\hline
\end{tabular}

2) He's got more gadgets on him than a Swiss army knife.

(Bo-Peep is describing the dazzling lights and buttons in Buzz Lightyear to Woody, who wanders teasingly about the toys fascination about him).

\begin{tabular}{|c|c|}
\hline $\begin{array}{l}\text { calque } \\
\text { literary } \\
\text { heaning } \\
\text { bortive } \\
\text { bizarre } \\
\text { diences } \\
\text { w a lot } \\
\text { army. } \\
\text { ards the } \\
\text { "knife" } \\
\text { versally } \\
\text { have }\end{array}$ & 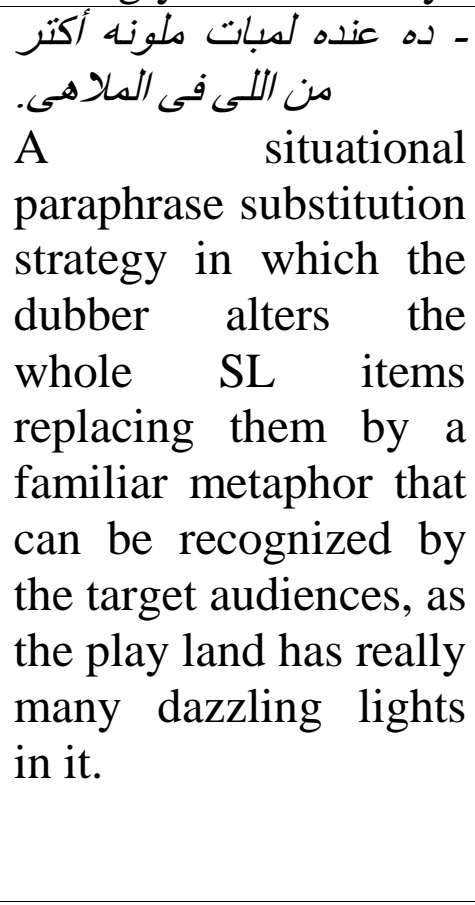 \\
\hline
\end{tabular}

3) It is a Combat Carl.

(A type of action figure line of toys resembling the American army; the toys are watching through the window Sid is preparing to blow up a toy soldier and wondering who is it, Woody sees through a binocular and says this segment).

\begin{tabular}{|c|c|c|}
\hline $\begin{array}{l}\text { - كارل انه بعنب كارل. } \\
\text { A specification by } \\
\text { explicitation strategy } \\
\text { that in which the } \\
\text { fansubber transfers } \\
\text { explains verbally what } \\
\text { is seen on the screen }\end{array}$ & $\begin{array}{l}\text { ـ } \\
\text { A sense transfer } \\
\text { strategy that provides } \\
\text { an explanation of the } \\
\text { meaning of the lexical } \\
\text { item, but again without } \\
\text { expounding the }\end{array}$ & $\begin{array}{l}\text { - إنه المقاتل كارل؛ - } \\
\text { A direct calque } \\
\text { strategy, in which the } \\
\text { MSA dubber adds the } \\
\text { word "لدقاتل to } \\
\text { convey the connotative }\end{array}$ \\
\hline
\end{tabular}




\section{Rania Abdel Baky Allam}

\begin{tabular}{|c|c|c|}
\hline $\begin{array}{l}\text { by the verbal } \\
\text { group "يعi". The CSR } \\
\text { is transferred as a } \\
\text { proper noun, which } \\
\text { does not give an } \\
\text { indication about the } \\
\text { cultural dimension of } \\
\text { the CRS item. }\end{array}$ & cultural dimension. & $\begin{array}{l}\text { asserting that it is the } \\
\text { toy soldier culturally } \\
\text { known in the SL } \\
\text { culture. }\end{array}$ \\
\hline
\end{tabular}

Table 3: Sample of Culture-Specific Refrences.

An analysis of the micro-strategies employed in translating CSRs yields many results. The fansubbed version employs SL oriented strategies by $73.32 \%$. He resorts to the safe, secured strategies that convey the literal meaning of the CSRs.

\begin{tabular}{|c|c|c|c|}
\hline Strategy & $\begin{array}{l}\text { Fansubbed } \\
\text { Version }\end{array}$ & $\begin{array}{l}\text { Colloquial Arabic } \\
\text { Dubbed Version }\end{array}$ & $\begin{array}{l}\text { MSA Dubbed } \\
\text { Version }\end{array}$ \\
\hline SL Oriented & $73.32 \%$ & $13.32 \%$ & $66.66 \%$ \\
\hline \multirow{7}{*}{$\begin{array}{l}\text { Retention } \\
\text { Complete } \\
\text { Retention } \\
\text { Specification } \\
\text { Explicitation } \\
\text { Direct } \\
\text { Translation } \\
\text { Calque } \\
\text { Shifted }\end{array}$} & $20 \%$ & $6.66 \%$ & $20 \%$ \\
\hline & $20 \%$ & $6.66 \%$ & $20 \%$ \\
\hline & $6.66 \%$ & $0 \%$ & $0 \%$ \\
\hline & $6.66 \%$ & $0 \%$ & $0 \%$ \\
\hline & $46.66 \%$ & $6.66 \%$ & $46.66 \%$ \\
\hline & $46.66 \%$ & $6.66 \%$ & $26.66 \%$ \\
\hline & $0 \%$ & $0 \%$ & $20 \%$ \\
\hline TL Oriented & $26.66 \%$ & $86.65 \%$ & $33.32 \%$ \\
\hline \multirow{6}{*}{$\begin{array}{l}\text { Generalization } \\
\text { Hyponymy } \\
\text { Other } \\
\text { Substitution } \\
\text { Cultural }\end{array}$} & $19.99 \%$ & $20 \%$ & $13.33 \%$ \\
\hline & $13.33 \%$ & $20 \%$ & $13.33 \%$ \\
\hline & $6.66 \%$ & $0 \%$ & $0 \%$ \\
\hline & $0 \%$ & $66.65 \%$ & $13.33 \%$ \\
\hline & $0 \%$ & $19.99 \%$ & $6.66 \%$ \\
\hline & $0 \%$ & $13.33 \%$ & $0 \%$ \\
\hline \multirow{5}{*}{$\begin{array}{l}\text { Transcultural } \\
\text { TL } \\
\text { Cultural } \\
\text { Paraphrase } \\
\text { Sense } \\
\text { Transfer } \\
\text { Situational } \\
\text { Omission } \\
\end{array}$} & $0 \%$ & $6.66 \%$ & $6.66 \%$ \\
\hline & $0 \%$ & $46.66 \%$ & $6.66 \%$ \\
\hline & $0 \%$ & $20 \%$ & $0 \%$ \\
\hline & $0 \%$ & $26.66 \%$ & $6.66 \%$ \\
\hline & $6.66 \%$ & $0 \%$ & $6.66 \%$ \\
\hline
\end{tabular}

Table 4: Statistics of Culture-Specific Refrences.

However, he employs TL oriented strategies by $26.66 \%$ in some instances, such as: "suckin 'down Darjeeling", which is a type of Indian 
tea, is translated into "تشرب الشاى", a generalization by hyponymy. This is quite an adequate manipulation that illuminates the meaning in an acceptable, adequate way.

The Colloquial Arabic dubber employs SL oriented strategies with a very limited percentage of $13.32 \%$. This is done when it is the only option. Nevertheless, TL oriented strategies are employed extensively with a high percentage of $86.65 \%$, in an attempt to retain the cultural dimension of the CSRs, such as: "lunch box" "دبي لفة كباب", a situational paraphrase strategy, or, "I am from Mattel” "أنا خريج العباسية" ". Colloquial Arabic dubber resorts to transcultural substitution strategy that adds a humorous effect to the cartoon movie.

The MSA dubber employs SL oriented strategies with a rather percentage of $66.66 \%$. He decides to abide by the protected, tenable strategies in an attempt to communicate the accurate meaning of the CSRs but it does always yield apt results, like in "Nirvana is coming!"'(the name of paradise in Buddhism) "نبرفانا قادم". The complete retention strategy yields very bizarre, exotic results. He makes use of TL oriented strategies also with $33.32 \%$ to tactfully conveys the cultural dimension of the CRSs, such as: "Save it for the jury" (Mr. Potato Head is accusing Woody of murder and does not believe his plea) " وفر هذا "للقضاء" a TL cultural substitution strategy that conforms to the TL cultural legal system, so as to be familiar to the TL audience.

\subsubsection{Lingua-Specific Features}

\subsubsection{Lexico-Semantic Dimension}

The first linguistic dimension to be probed from a micro level of Pedersen's translational strategies is the lexico-semantic one. The following examples are exhibited as a sample of the comparative analysis carried out:

\section{ST Context}

A) Andy is playing with his toys- Mr. Potato Head as a burglar and Woody is catching him.

\section{SL Item}

1) Say good-bye to the wife and Tatertots. (A type of potato chips).

\begin{tabular}{|c|c|c|}
\hline Fansubbed Version & $\begin{array}{l}\text { Colloquial Arabic } \\
\text { Dubbed Version }\end{array}$ & $\begin{array}{l}\text { MSA Dubbed } \\
\text { Version }\end{array}$ \\
\hline $\begin{array}{l}\text { - قل وداعا لزوجتك وأولكدك. } \\
\text { A paraphrase by sense } \\
\text { transfer } \\
\text { explaining to the TL } \\
\text { audience the intended } \\
\text { ST meaning. }\end{array}$ & 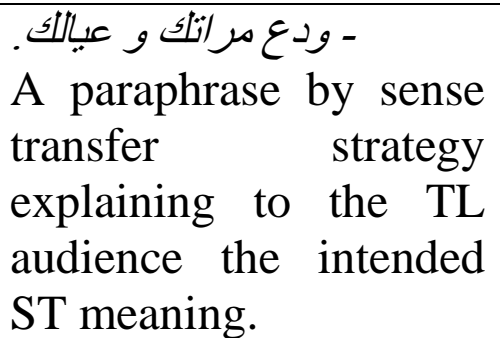 & 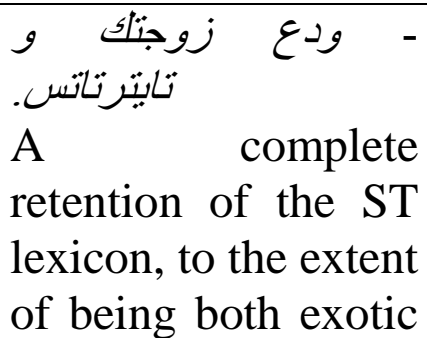 \\
\hline
\end{tabular}




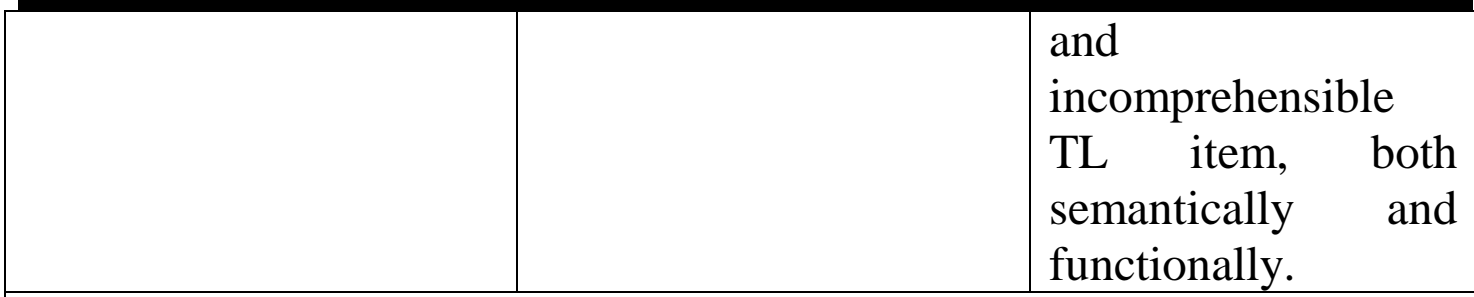

B) Bo-Peep is thanking Woody for saving her sheep and inviting him to spend some time with her.

2) Whadda say I get someone else to watch the sheep tonight?

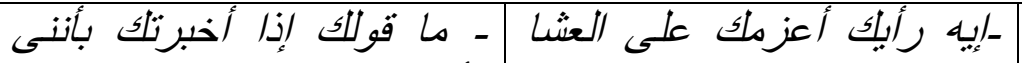

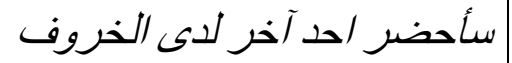
اللبلة؟

A direct calque strategy, that appears a little exotic to the TL audience.
في البيث عندى الليلة ديب؟

A situational paraphrase strategy, conveying the SL script message in a variant, yet comprehensible way to the TL audience.
ـ ما رأيك هل أحضرأحدا آخر لحراسة الخراف هذه الحراف الليلة؟

A direct calque strategy that superficially provides the direct meaning without expressing the intended functional meaning of the whole translational segment, which is an indirect invitation for an outing.

C) Woody is praising the excellent painting of Itch-a-Sketch the toy.

3) Fastest knobs in the west.

\section{ـ أنت أسر ع رسام في الغرب.}

A paraphrase by sense transfer strategy, by replacing "knob" with"رسام"explaining to the TL audience the intended ST meaning.

A situational paraphrase
strategy, replacing the
whole SL segment with
another explaining by
using two praising
adjectival groups the
intended functional
meaning.
ـ أسرع مقبض فى الغرب. Again a direct calque strategy that superficially provides a literal meaning which entails strangeness in the TL script, rendering the dialogue odd and unfamiliar.

None of the three AVT versions gives an explanation of the "west" " in this context, which most probably stems from Woody's western American background as a cowboy.

Table 5: Sample of Lexico-Semantic Dimensions. 
An extensive analysis of the micro-strategies employed in translating the lexico-semantic dimension of the SL script shows the following results:

The fansubbing translation is SL oriented with the direct translation as the highest degree, especially the calque strategy. This indicates that the fansubber lacks the translation techniques maneuvers, on the one hand, and resorts to the safest translational haven, on the other. Nevertheless, even such SL oriented translation strategy is not free of erroneous interpretations

and exotic retentions. For instance, "moving buddy", which contextually means that each toy picks another one to stick with during the family's moving to another house, is translated by calque as "رفيق متحرك". Similarly, "double $A A s$ " (means batteries) is translated by calque

\begin{tabular}{|c|c|c|c|}
\hline Strategy & $\begin{array}{l}\text { Fansubbed } \\
\text { Version }\end{array}$ & $\begin{array}{l}\text { Colloquial Arabic } \\
\text { Dubbed Version }\end{array}$ & $\begin{array}{l}\text { MSA Dubbed } \\
\text { Version }\end{array}$ \\
\hline SL Oriented & $62.32 \%$ & $23.27 \%$ & $63.8 \%$ \\
\hline \multirow{9}{*}{$\begin{array}{l}\text { Retention } \\
\text { Complete } \\
\text { Retention } \\
\text { Adjusted } \\
\text { Specification } \\
\text { Explicitation } \\
\text { Addition } \\
\text { Direct } \\
\text { Translation } \\
\text { Calque } \\
\text { Shifted }\end{array}$} & $2.05 \%$ & $0.68 \%$ & $2.73 \%$ \\
\hline & $2.05 \%$ & $0 \%$ & $2.05 \%$ \\
\hline & $0 \%$ & $0.68 \%$ & $0.68 \%$ \\
\hline & $0 \%$ & $4.1 \%$ & $2.05 \%$ \\
\hline & $0 \%$ & $3.42 \%$ & $2.05 \%$ \\
\hline & $0 \%$ & $0.68 \%$ & $0 \%$ \\
\hline & $60.27 \%$ & $18.49 \%$ & $58.9 \%$ \\
\hline & $57.53 \%$ & $15.07 \%$ & $53.42 \%$ \\
\hline & $2.74 \%$ & $3.42 \%$ & $5.48 \%$ \\
\hline TL Oriented & $37.65 \%$ & $76.7 \%$ & $36.28 \%$ \\
\hline \multirow{6}{*}{$\begin{array}{l}\text { Generalization } \\
\text { Hyponymy } \\
\text { Other } \\
\text { Substitution } \\
\text { Cultural }\end{array}$} & $7.53 \%$ & $6.16 \%$ & $2.74 \%$ \\
\hline & $4.79 \%$ & $3.42 \%$ & $1.37 \%$ \\
\hline & $2.74 \%$ & $2.74 \%$ & $1.37 \%$ \\
\hline & $21.22 \%$ & $65.75 \%$ & $24.64 \%$ \\
\hline & $0.68 \%$ & $13.7 \%$ & $2.73 \%$ \\
\hline & $0 \%$ & $12.33 \%$ & $0.68 \%$ \\
\hline \multirow{5}{*}{$\begin{array}{l}\text { Transcultural } \\
\text { TL } \\
\text { Cultural } \\
\text { Paraphrase } \\
\text { Sense } \\
\text { Transfer } \\
\text { Situational } \\
\text { Omission }\end{array}$} & $0.68 \%$ & $1.37 \%$ & $2.05 \%$ \\
\hline & $20.54 \%$ & $52.05 \%$ & $21.91 \%$ \\
\hline & $17.8 \%$ & $30.82 \%$ & $18.49 \%$ \\
\hline & $2.74 \%$ & $21.23 \%$ & $3.42 \%$ \\
\hline & $8.9 \%$ & $4.79 \%$ & $8.9 \%$ \\
\hline
\end{tabular}

Table 6: Statistics of Lexico-Semantic Dimensions. 


\section{Rania Abdel Baky Allam}

as "ضr". "O.R." which means "operation room" or غرفة العمليات is

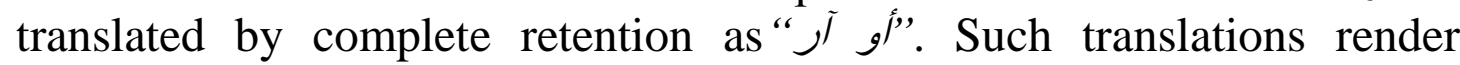
bizarre, unreflective meaning resulting in misperceptions and weak comprehensibility of the fansubbed version of the movie. As for the TL oriented translation strategy, he, in some instances, employs the transcultural technique quite tactfully as translating "May Day", a wellknown call for help as "ستغاثة").

The Colloquial Arabic dubbed translation is primarily TL oriented with the paraphrasing and cultural substitution at a high degree, especially the sense transfer strategy. This points out that the Arabic Colloquial Arabic dubber manipulates the translational techniques so as to render the TL script quite adequate and acceptable in the TC and to the target recipient. Such TL oriented translation strategy sets the script in the TL linguistic and artistic milieu to the extent that, in some instances, the TL script seems originally written in the Colloquial Arabic, a trait considered by many scholars, other than Venuti, a translational proficiency. For instance, "staff meeting”, is translated by transcultural transfer as "جتماع (جتو ". Similarly, "laser envy" (which contextually refers to the laser beam which buzz Lightyear has and Woody lacks) is translated by situational paraphrase as "ده غيران قوى". "Astro-turf", which indicates a space related matter, is translated by complete retention by the fansubbed, while in this version it is translated by using a situational paraphrase as "موتورها كمان ذرى". Such techniques are both lexically and semantically functional, well-contrived and reflective, especially bearing in mind the fact that they are children-oriented.

The MSA dubbed translation is mainly SL oriented with the direct translation at the highest degree, especially the calque strategy. This is quite close to the fansubbed version with the exception of using more TL substitution strategies with sense transfer as the most common strategy. Nevertheless, even such SL oriented translation strategy, either by calque or shift, sometimes renders invalid interpretations and foreign retentions. For instance, "moving buddy" is translated by calque as "جسد متحرك" (apparently the MSA translator uses the acoustic SL script version without resorting to a written one, thus he hears "buddy" as body, rendering the translation quite exotic. Similarly, "double AAs" (means batteries) is translated by complete retention as "بطاريات دبل أبيه" and

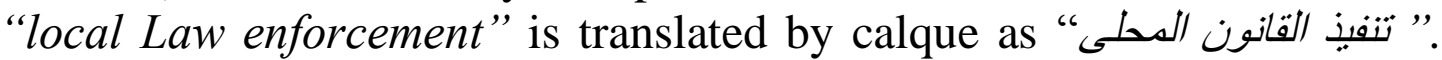
As for the TL oriented translation strategy, he, in some instances employs the situational paraphrase with no obvious reason resulting in inaccurate translation "I sure hope this isn't permanent" (Sid burns Woody's plastic

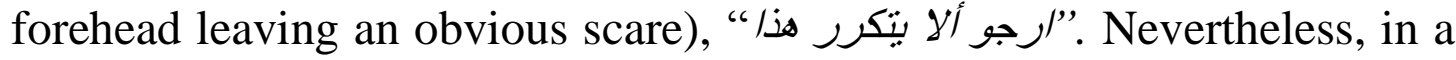
few instances, he resorts to TL oriented strategies to produce a tactful 
translation segment (a fact quite strange as the MSA dubbing company is supposed to produce more professional translation than the fansubbed version), like in; "Mission Control", he employs the TL cultural strategy “برجة الدراقبة".

\subsubsection{Pragmatic Dimension}

\subsection{Proper Nouns}

Although proper nouns (anthroponyms and toponyms), names of people or places- are not considered by Chiaro as a pragmatic dimension, they imply many semantic and sometimes semiotic shades of meaning which have to do with the SL culture, as Fernandes (2006) asserts. Therefore, they are quite problematic areas in translation. Moreover, they are so much associated with the forms of address, thus they are analyzed within the pragmatic realm.

Personal-names comprise a translation difficulty in all types of texts. Jaleniauskiené and Čičelyté (2009, p. 31) point out that the translation of proper nouns is one of the most challenging activities, "since proper names usually have various allusions indicating sex, age, geographical belonging, history, specific meaning, playfulness of language and cultural connotations." Al-Alami (2006, p. 53) proposes that translators use neologisms with difficult meanings and manipulate some words to make cartoon names humorous.

The names of toys in the movie under study imply some SL semantic shades. The names are derived from the actual description and shape. For instance, Mr. Potato Head is a toy in the shape of a potato human head, Mr. Spell is a board displaying the spelling of words, Etch is an (Etch-a-Sketch) board, Slinky is a dog with a stretchy slink in the middle of his body, $R C$ is a car that moves with a remote control $\mathrm{RC}$, while Robot, Pump-Boy, Ducky, Roller Bob are exactly toys representing such names (a robot, a bump boy, a duck and a roller car). The following examples are displayed as a sample of the comparative analysis of proper nouns carried out to figure out how the three versions rendered the translation of names:

\begin{tabular}{|c|c|}
\hline SL Names & $\begin{array}{l}\text { Andy, Bo-Peep, Mr. Potato Head, Mr. Spell, Snake, Robot, } \\
\text { Etch (Etch-a-Sketch), Buzz Lightyear, Sid, RC, Pizza } \\
\text { Planet, Whiskers, Al's Toy Barn, Mrs. Nesbit, Pump-Boy, } \\
\text { Ducky, Legs, Roller Bob, Motherboard, Mrs. Potato Head. }\end{array}$ \\
\hline $\begin{array}{l}\text { Fansubbed } \\
\text { Version }\end{array}$ & 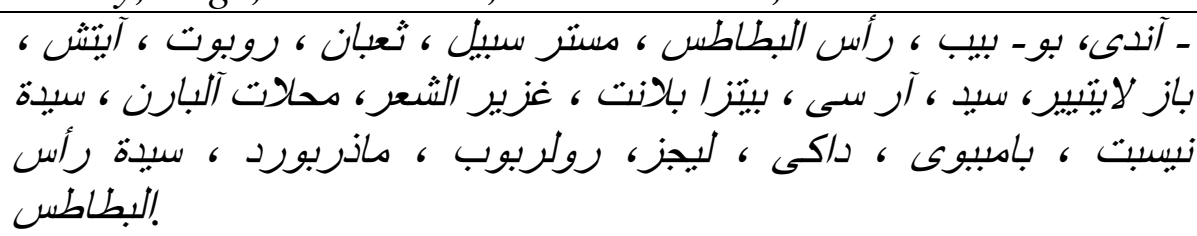 \\
\hline $\begin{array}{l}\text { Colloquial } \\
\text { Arabic }\end{array}$ & 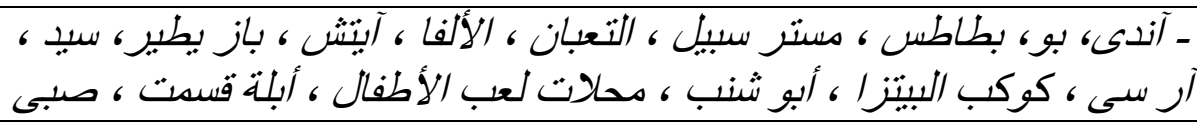 \\
\hline & $\begin{array}{l}\text { Occasional Papers } \\
\text { Vol. 62(Dec. 2016) }\end{array}$ \\
\hline
\end{tabular}




\begin{tabular}{|c|c|}
\hline $\begin{array}{l}\text { Dubbed } \\
\text { Version }\end{array}$ & سباك ، البطة ، رجل ، العربية ، غرفة المر/قبة ، مدام بطاطس. \\
\hline $\begin{array}{l}\text { MSA } \\
\text { Dubbed } \\
\text { Version }\end{array}$ & 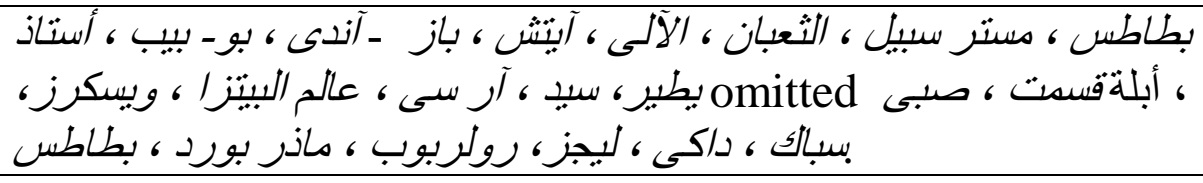 \\
\hline
\end{tabular}

Table 7: Sample of Proper Nouns.

An analysis of the micro-strategies employed in translating the proper names, whether semantically loaded or a just a proper name in the SL script, shows the following results:

Both the fansubbed and MSA dubbed versions mainly employ the complete retention strategy with nearly similar percentage of 80 and $72 \%$. The fansubber and the MSA dubber opt for translating the names in a few instances using either calque or shifted direct translation strategies, like in "رأس البطاطس" or "successively. TL oriented strategies, like sense transfer, is used with only $4 \%$ in each, like in translating "Whiskers" as "غزير الثعر" in the fansubbed version and "Pizza Planet" as " in the MSA dubbed one. This renders the translation quite foreignized and TL oriented.

\begin{tabular}{|c|c|c|c|}
\hline Strategy & $\begin{array}{l}\text { Fansubbed } \\
\text { Version }\end{array}$ & $\begin{array}{l}\text { Colloquial Arabic } \\
\text { Dubbed Version }\end{array}$ & $\begin{array}{l}\text { MSA Dubbed } \\
\text { Version }\end{array}$ \\
\hline SL Oriented & $96 \%$ & $\mathbf{7 2 \%}$ & $84 \%$ \\
\hline \multirow{7}{*}{$\begin{array}{l}\text { Retention } \\
\text { Complete } \\
\text { Retention } \\
\text { Specification } \\
\text { Explicitation } \\
\text { Direct Translation } \\
\text { Calque } \\
\text { Shifted }\end{array}$} & $80 \%$ & $40 \%$ & $72 \%$ \\
\hline & $80 \%$ & $40 \%$ & $72 \%$ \\
\hline & $4 \%$ & $0 \%$ & $0 \%$ \\
\hline & $4 \%$ & $0 \%$ & $0 \%$ \\
\hline & $12 \%$ & $32 \%$ & $12 \%$ \\
\hline & $12 \%$ & $28 \%$ & $8 \%$ \\
\hline & $0 \%$ & $4 \%$ & $4 \%$ \\
\hline TL Oriented & $4 \%$ & $28 \%$ & $16 \%$ \\
\hline \multirow{9}{*}{$\begin{array}{l}\text { Generalization } \\
\text { Hyponymy } \\
\text { Other } \\
\text { Substitution } \\
\text { Cultural } \\
\text { Transcultural } \\
\text { Paraphrase } \\
\text { Sense Transfer } \\
\text { Omission }\end{array}$} & $0 \%$ & $12 \%$ & $4 \%$ \\
\hline & $0 \%$ & $4 \%$ & $0 \%$ \\
\hline & $0 \%$ & $8 \%$ & $4 \%$ \\
\hline & $4 \%$ & $12 \%$ & $4 \%$ \\
\hline & $0 \%$ & $12 \%$ & $0 \%$ \\
\hline & $0 \%$ & $12 \%$ & $0 \%$ \\
\hline & $4 \%$ & $0 \%$ & $4 \%$ \\
\hline & $4 \%$ & $0 \%$ & $4 \%$ \\
\hline & $0 \%$ & $0 \%$ & $4 \%$ \\
\hline $\begin{array}{l}\text { Official } \\
\text { Equivalent }\end{array}$ & $0 \%$ & $4 \%$ & $4 \%$ \\
\hline
\end{tabular}

Table 8: Statistics of Proper Nouns. 
Similarly, the MSA dubbed version employs complete retention strategy with a $72 \%$ percent. Direct translation strategy is also employed with the shifted type with a higher percentage than calque, like in translating "Mrs. Potato Head" as "أستاذ بطاطس", with the exception of employing the official equivalent strategy in the two dubbed versions Egyptian and MSA dubbed versions in translating "Buzz Lightyear" as "باز يطير”. Both the fansubbed and MSA dubbed versions do not refer to the semantic and cultural allusions of names.

On the other hand, the Egyptian dubber tries in $28 \%$ of the names to be TL oriented trying mainly to find transcultural equivalents for the name, such as: “الألفا ، أبو شنب ، أبلة قسى ، غرفة المراقبة". Even when he resorts to ST oriented strategies, he employs direct translation with nearly $32 \%$, trying to find equivalents for the semantic meanings of the name,

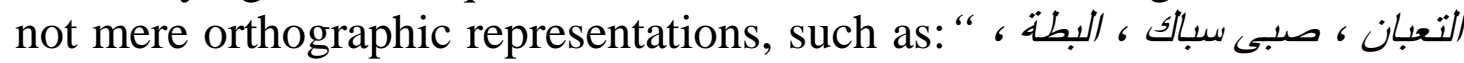
( رجل ، Again, this indicates that the Colloquial Arabic dubber takes into consideration the semantic and cultural dimensions of the name, to render the TL script quite adequate and acceptable in the TC and to the target recipient.

\subsection{Forms of Address}

As for the forms of address as a pragmatic aspect, they are considered by Chiaro (2009) a fuzzy area that is relatively posing some translational difficulties. The following examples are demonstrated as a sample of the comparative analysis for the forms of address in the three versions:

SL Forms of Address: Sarge, Star Command, Gas Dude, little fellah, man,

\begin{tabular}{|c|c|c|}
\hline Fansubbed Version & $\begin{array}{l}\text { Colloquial Arabic } \\
\text { Dubbed Version }\end{array}$ & $\begin{array}{l}\text { MSA Dubbed } \\
\text { Version }\end{array}$ \\
\hline 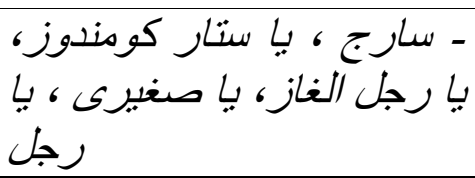 & 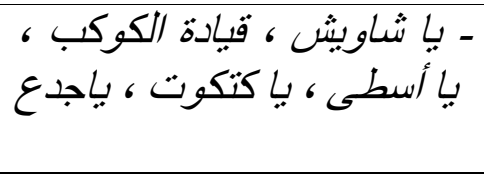 & 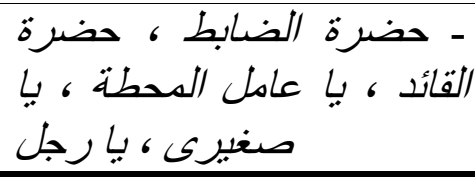 \\
\hline
\end{tabular}

Table 9: Sample of Forms of Address.

An analysis of the micro-strategies employed in translating the forms of address shows the following results: 
Rania Abdel Baky Allam

Both the fansubbed and MSA dubbed versions mainly employ the

\begin{tabular}{|c|c|c|c|}
\hline Strategy & $\begin{array}{c}\text { Fansubbed } \\
\text { Version }\end{array}$ & $\begin{array}{l}\text { Colloquial Arabic } \\
\text { Dubbed Version }\end{array}$ & $\begin{array}{l}\text { MSA Dubbed } \\
\text { Version }\end{array}$ \\
\hline SL Oriented & $85.7 \%$ & $52.37 \%$ & $71.34 \%$ \\
\hline \multirow{8}{*}{$\begin{array}{l}\text { Retention } \\
\text { Complete } \\
\text { Retention } \\
\text { Adjusted } \\
\text { Specification } \\
\text { Addition } \\
\text { Direct } \\
\text { Translation } \\
\text { Calque } \\
\text { Shifted }\end{array}$} & $14.28 \%$ & $4.76 \%$ & $9.52 \%$ \\
\hline & $9.52 \%$ & $4.76 \%$ & $4.76 \%$ \\
\hline & $4.76 \%$ & $0 \%$ & $4.76 \%$ \\
\hline & $0 \%$ & $9.52 \%$ & $0 \%$ \\
\hline & $0 \%$ & $9.52 \%$ & $0 \%$ \\
\hline & $71.42 \%$ & $38.09 \%$ & $61.82 \%$ \\
\hline & $66.66 \%$ & $33.33 \%$ & $52.3 \%$ \\
\hline & $4.76 \%$ & $4.76 \%$ & $9.52 \%$ \\
\hline TL Oriented & $14.28 \%$ & $47.61 \%$ & $28.56 \%$ \\
\hline \multirow{6}{*}{$\begin{array}{l}\text { Generalization } \\
\text { Hyponymy } \\
\text { Other } \\
\text { Substitution } \\
\text { Cultural }\end{array}$} & $4.76 \%$ & $0 \%$ & $14.28 \%$ \\
\hline & $4.76 \%$ & $0 \%$ & $4.76 \%$ \\
\hline & $0 \%$ & $0 \%$ & $9.52 \%$ \\
\hline & $9.52 \%$ & $47.61 \%$ & $9.52 \%$ \\
\hline & $0 \%$ & $38.09 \%$ & $9.52 \%$ \\
\hline & $0 \%$ & $38.09 \%$ & $9.52 \%$ \\
\hline \multirow{4}{*}{$\begin{array}{l}\text { Transcultural } \\
\text { Paraphrase } \\
\text { Sense } \\
\text { Transfer } \\
\text { Situational } \\
\text { Omission }\end{array}$} & $9.52 \%$ & $9.52 \%$ & $0 \%$ \\
\hline & $9.52 \%$ & $4.76 \%$ & $0 \%$ \\
\hline & $0 \%$ & $4.76 \%$ & $0 \%$ \\
\hline & $0 \%$ & $0 \%$ & $4.76 \%$ \\
\hline
\end{tabular}

Table 10: Statistics of Forms of Address.

direct translation strategy with 71.42 and $61.82 \%$. Besides, 66.66 and $52.3 \%$ of both percentages are calque. This can be exemplified in: "birthday boy" and "Sir". They are translated in the fansubbed version

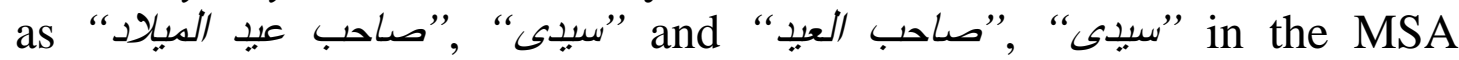
dubbed version. Moreover, the fansubber uses both types of retention with a total of $14.28 \%$, as in; "ستار كومندوز" " opts for the same but with lesser percentage of $4.76 \%$ for each retention type, as in; "Hana" and "Sheriff Woody" "انا"ا" "الثريف وودى". In the fansubbed and MSA dubbed versions TL oriented strategies, like sense transfer "Sheriff Woody" "الثرطى ووديى" (fansubbed), or generalization "Lizard and Stretchy Dog" "أنتحا الاثنبن" (MSA dubbed) are used with low percentages; 9.52\% (sense transfer in the fansubbed) and $9.52 \%$ also (generalization in the MSA dubbed). The two translators do not exert 
much effort to come closer to the TL to domesticate the produced script so as to be more acceptable or familiar to the TC audience. They retain its foreignized flavor even in the forms of address.

On the contrary, the Egyptian dubber tries in $52.37 \%$ of the forms of address to use a functional, domesticated translation that are transmitted culturally to the audience to be adequate and recognizable. He employs a close strategy to the TL namely transcultural substitution with 42.85\% (a rather high one), like in; "يا شاويش، يا هندسة، يا كتكوت". The Colloquial Arabic dubber still adopts the TL oriented strategies that tend to render his script closer and adequate to the target recipient.

\subsection{Swear Words}

Taboos and swear words are considered by Chiaro as a pragmatic dimension. The following examples are a sample of the comparative analysis of swear words in three versions:

\begin{tabular}{|c|c|c|}
\hline $\begin{array}{l}\text { SL Swear Words: } \\
\text { Princess Drool, lightsna }\end{array}$ & $k$, did you all take stupic & pills, disgusting freaks. \\
\hline Fansubbed Version & $\begin{array}{l}\text { Colloquial Arabic } \\
\text { Dubbed Version }\end{array}$ & $\begin{array}{c}\text { MSA Dubbed } \\
\text { Version }\end{array}$ \\
\hline 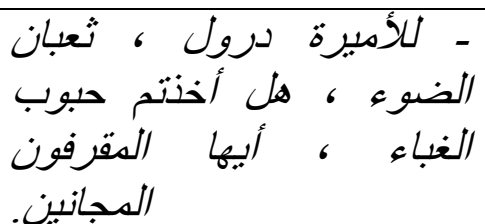 & ، أنتوا واكلبين فيبالة ، با بتاع أنت ، جاتكوا & 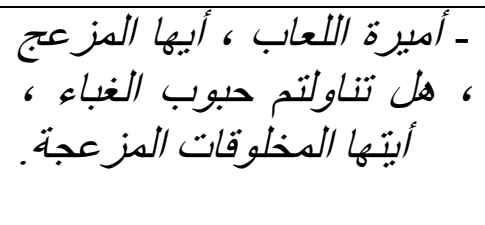 \\
\hline
\end{tabular}

Table 11: Sample of Swear Words.

\begin{tabular}{|c|c|c|c|}
\hline Strategy & $\begin{array}{l}\text { Fansubbed } \\
\text { Version }\end{array}$ & $\begin{array}{l}\text { Colloquial Arabic } \\
\text { Dubbed Version }\end{array}$ & $\begin{array}{l}\text { MSA Dubbed } \\
\text { Version }\end{array}$ \\
\hline SL Oriented & $66.66 \%$ & $33.33 \%$ & $42.42 \%$ \\
\hline \multirow{5}{*}{$\begin{array}{l}\text { Retention } \\
\quad \text { Complete } \\
\text { Retention } \\
\text { Direct } \\
\text { Translation } \\
\text { Calque } \\
\text { Shifted }\end{array}$} & $3.03 \%$ & $0 \%$ & $0 \%$ \\
\hline & $3.03 \%$ & $0 \%$ & $0 \%$ \\
\hline & $63.63 \%$ & $33.33 \%$ & $42.42 \%$ \\
\hline & $54.54 \%$ & $24.24 \%$ & $39.39 \%$ \\
\hline & $9.09 \%$ & $9.09 \%$ & $3.03 \%$ \\
\hline TL Oriented & $33.33 \%$ & $66.66 \%$ & $57.57 \%$ \\
\hline \multirow{10}{*}{$\begin{array}{l}\text { Generalization } \\
\text { Hyponymy } \\
\text { Other } \\
\text { Substitution } \\
\text { Cultural } \\
\text { Transcultural } \\
\text { Paraphrase } \\
\text { Sense } \\
\text { Transfer } \\
\text { Situational } \\
\text { Omission }\end{array}$} & $6.06 \%$ & $0 \%$ & $6.06 \%$ \\
\hline & $6.06 \%$ & $0 \%$ & $0 \%$ \\
\hline & $0 \%$ & $0 \%$ & $6.06 \%$ \\
\hline & $12.12 \%$ & $48.48 \%$ & $33.33 \%$ \\
\hline & $0 \%$ & $12.12 \%$ & $0 \%$ \\
\hline & $0 \%$ & $12.12 \%$ & $0 \%$ \\
\hline & $12.12 \%$ & $36.36 \%$ & $33.33 \%$ \\
\hline & $12.12 \%$ & $24.24 \%$ & $24.24 \%$ \\
\hline & $0 \%$ & $12.12 \%$ & $9.09 \%$ \\
\hline & $15.15 \%$ & $18.18 \%$ & $4 \%$ \\
\hline
\end{tabular}


Table 12: Statistics of Swear Words.

An analysis of the micro-strategies employed in translating swear words proves that the fansubbed version principally employs the direct translation strategy with $60.6 \%, 51.51 \%$ of them for calque. He also resorts to complete retention in translating "Princess Drool", as in the context that is meant to be an offensive comment for baby Molly who sucks Potato Head toy and kicks against her crib loosening his parts. The Colloquial Arabic dubber provides a transcultural swear word that fits in exactly to the context "للبنت أم ريالة". While the MSA dubber resorts to an easy alternative, calque "مبيرة اللعاب"," an exotic translation in the TC.

Besides, the Colloquial Arabic dubber tries to provide TL oriented alternatives for the swear words by transcultural equivalents $12.12 \%$ and paraphrase strategies 36.36\%, as in the ST segment; "نتوا واكليين فول" a characteristic transcultural alternative, quite meaningful, expressive and typical to the TL Egyptian culture, and the ST segment; "you sunk it" " "ضلالى انت بتغش a situational paraphrase strategy which is employed to illuminate the idiomatic meaning of the swear word, reflecting both its semantic and functional meaning with much concern to the cultural dimension.

The MSA dubber is resorting to ST and TL oriented strategies with nearly equal percentages. However, he uses the equivalent "مزعج" in $24.24 \%$ of the examples, even if it is not the accurate equivalent. This can be attributed to censorship considerations, being a cartoon movie and swear words have to be restricted and confined. This can also explain the relatively high percentage of omission strategy in the fansubbed and Colloquial Arabic dubbed versions; $15.15 \%$ and $18.18 \%$.

\subsubsection{Visual Verbal Versus Spoken}

The visual verbal element is supposed to be conforming to the spoken dialogue so as to achieve audio visual translation professionalism. It entails translational manipulation also. The following examples are a sample of the comparative analysis of such elements in the three versions:

ST Context: A) Woody is praising the troop of plastic toy soldiers he sends to investigate about Andy's birthday gifts, but ironically the audience see them lying on the ground after a huge fall.

SL Item: 1) They are not lying down on the job.

\begin{tabular}{|c|c|c|}
\hline Fansubbed VeI & & $\begin{array}{r}\text { MSA } \\
\text { Ve }\end{array}$ \\
\hline $\begin{array}{l}\text { - إنهم لن بناموا فى العهل } \\
\text { A direct shif } \\
\text { strategy that conv } \\
\text { the meaning of }\end{array}$ & 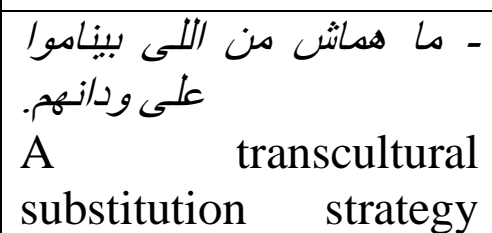 & 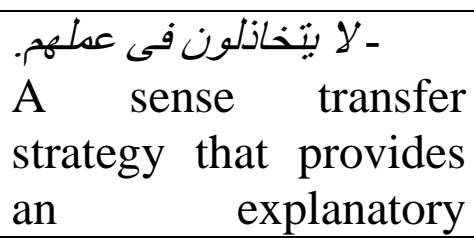 \\
\hline
\end{tabular}




\begin{tabular}{|c|c|c|}
\hline alertness accurately. & $\begin{array}{l}\text { employing the } \\
\text { idiomatic Egyptian } \\
\text { term a cultural } \\
\text { نايم على ودنه } \\
\text { cliché, expressing } \\
\text { laziness on the job- } \\
\text { quite comprehended by } \\
\text { the TL audience. }\end{array}$ & $\begin{array}{l}\text { meaning to the SL } \\
\text { segment, employing } \\
\text { the verbal group } \\
\text { same denotations of } \\
\text { the SL segment. }\end{array}$ \\
\hline
\end{tabular}

B) Woody is mocking Buzz for believing he can stop Sid from blowing up toys, while visually on the screen a black crater hole is seen in Sid's backyard as remains of the blown-up toy soldier.

2) I would love to see you as a crater.

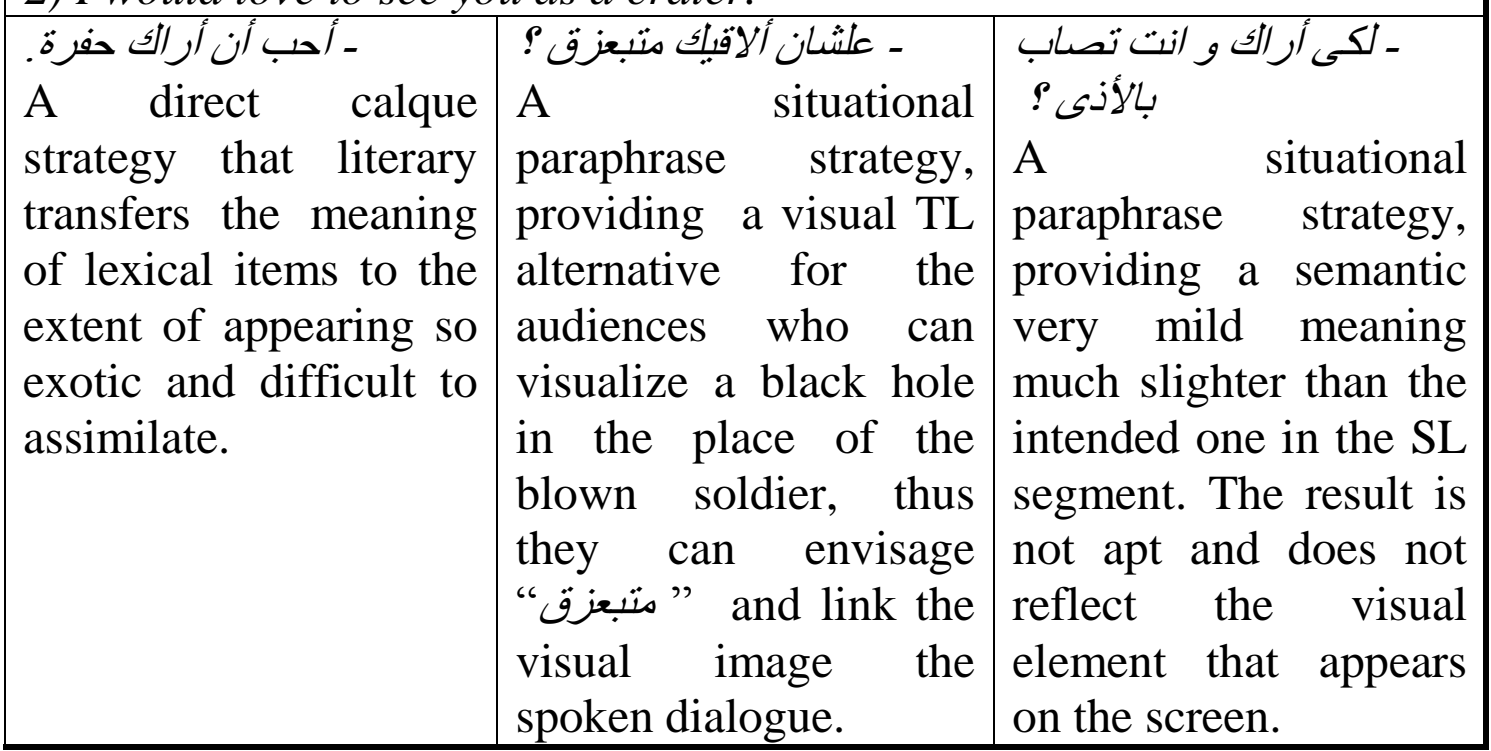

Table 13: Sample of Visual Verbal Versus Spoken.

An analysis of the micro-strategies employed in translating visual verbal versus spoken element exhibits that the fansubber employs the direct translation strategy with $100 \%$. He sticks to transferring the SL segments literally. The Colloquial Arabic dubber employs TL oriented strategies by $80 \%$ with $60 \%$ for paraphrase only. The MSA dubber employs TL oriented strategies by $60 \%$.

\begin{tabular}{|l|c|c|c|}
\hline \multirow{2}{*}{ Strategy } & $\begin{array}{c}\text { Fansubbed } \\
\text { Version }\end{array}$ & $\begin{array}{c}\text { Colloquial } \\
\text { Arabic Dubbed } \\
\text { Version }\end{array}$ & $\begin{array}{c}\text { MSA Dubbed } \\
\text { Version }\end{array}$ \\
\hline SL Oriented & $\mathbf{1 0 0 \%}$ & $\mathbf{2 0 \%}$ & $\mathbf{4 0 \%}$ \\
\hline $\begin{array}{l}\text { Direct } \\
\text { Translation } \\
\begin{array}{l}\text { Calque } \\
\text { Shifted }\end{array}\end{array}$ & $100 \%$ & $20 \%$ & $40 \%$ \\
\cline { 2 - 4 } & $60 \%$ & $20 \%$ & $20 \%$ \\
\hline
\end{tabular}


Rania Abdel Baky Allam

\begin{tabular}{|c|c|c|c|}
\hline TL Oriented & $\mathbf{0 \%}$ & $\mathbf{8 0 \%}$ & $\mathbf{6 0 \%}$ \\
\hline Substitution & $0 \%$ & $80 \%$ & $60 \%$ \\
\cline { 2 - 4 } Cultural & $0 \%$ & $20 \%$ & $0 \%$ \\
\cline { 2 - 4 } & $0 \%$ & $20 \%$ & $0 \%$ \\
\cline { 2 - 4 } Transcultural & $0 \%$ & $60 \%$ & $60 \%$ \\
\cline { 2 - 4 } Paraphrase & $0 \%$ & $40 \%$ & $40 \%$ \\
\cline { 2 - 4 } Sense & $0 \%$ & $20 \%$ & $20 \%$ \\
Transfer & & & \\
Situational & & & \\
\hline
\end{tabular}

Table 14: Statistics of Visual Verbal-Versus Spoken.

For instance, when Woody is holding an end of a Christmas light wire and throwing the other end to his toy friends through the window Mr. Potato Head is suspicious about him and refuses to tie it to anything, so Woody can reach to the other side of Andy's room; Mr. Potato Head says "What are you trying to pull? It is fansubbed as " ما الذى تحاول جنبه" and dubbed in the Colloquial Arabic as "نت "نتحاول تقنعنا بإيه؟" and dubbed in MSA as "ما الذى تحاول أن تفعله". Although the Colloquial Arabic and MSA dubbers employ TL oriented strategies, yet they do not give a heed for the visual element, just conveying the intended functional meaning, while, on the contrary, the direct fansubbing translation exhibits such visual dimension.

\subsubsection{Fuzzy Areas}

\subsubsection{Songs}

There are three songs in the film under study which are translated. The TL songs which pertain to such stipulations are the ones translated in the dubbed Colloquial Arabic version. As for the fansubbed version meanings, they are directly pertained without much concern to the technical and rhetorical constraints of rhythmic discourse. In the dubbed MSA version the translator tries to convey the meaning while keeping the rhythmic spirit of the original. However, the end result was not that appropriate either lexically or aesthetically.

The following examples are demonstrated as a sample of the comparative analysis of musical code, the verbal one in the three versions:

\begin{tabular}{|c|c|c|c|}
\hline SL Item & $\begin{array}{c}\text { Fansubbed } \\
\text { Version }\end{array}$ & $\begin{array}{c}\text { Colloquial } \\
\text { Arabic Dubbed } \\
\text { Version }\end{array}$ & $\begin{array}{c}\text { MSA } \\
\text { Dubbed } \\
\text { Version }\end{array}$ \\
\hline $\begin{array}{l}\text { Song 1: } \\
\text { You got a friend } \\
\text { in me, } \\
\text { When the road }\end{array}$ & 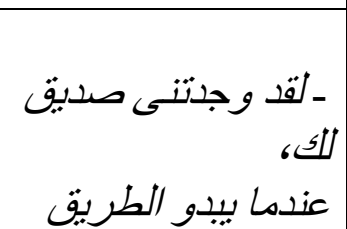 & ـ أنا أنا الصدأييء اللى قئيى، & ـ أنا صديقاك أنا. \\
\hline
\end{tabular}




\begin{tabular}{|c|c|c|c|}
\hline $\begin{array}{l}\text { looks rough } \\
\text { ahead, } \\
\text { You are miles } \\
\text { and miles from } \\
\text { your warm bed, } \\
\text { You just } \\
\text { remember what } \\
\text { your old pal said, } \\
\text { You got a friend } \\
\text { in me, }\end{array}$ & 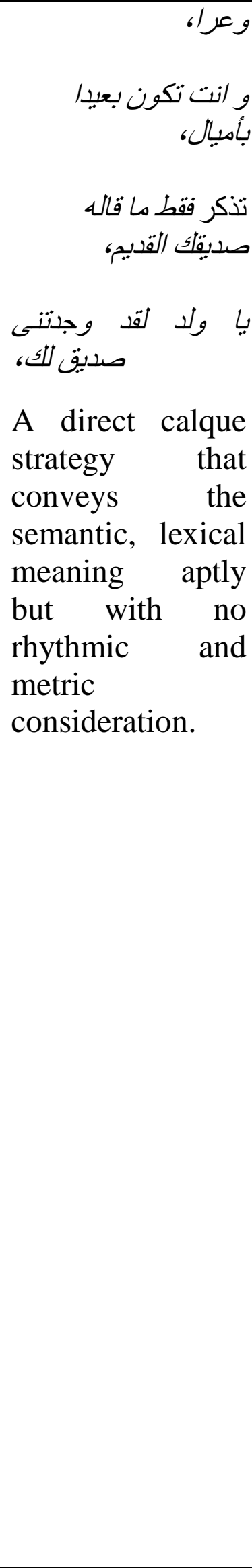 & 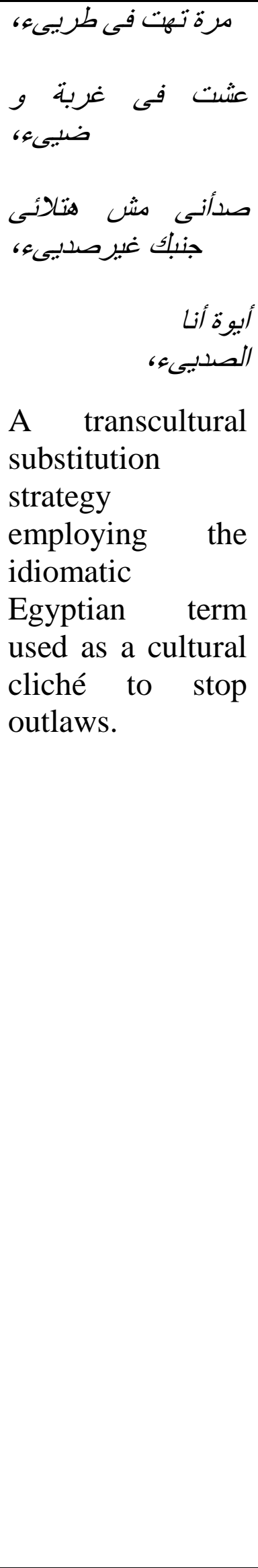 & $\begin{array}{l}\text { The } \\
\text { translation } \\
\text { in this } \\
\text { version is a } \\
\text { mixture of } \\
\text { calque, } \\
\text { sense } \\
\text { transfer and } \\
\text { situational } \\
\text { substitution } \\
\text { strategies, in } \\
\text { an attempt to } \\
\text { keep the } \\
\text { balance of } \\
\text { meaning and } \\
\text { form in the } \\
\text { song. } \\
\text { Nonetheless, } \\
\text { the dubber } \\
\text { committed a } \\
\text { very strange } \\
\text { mistake } \\
\text { completely } \\
\text { out of } \\
\text { context, as } \\
\text { the song is } \\
\text { written and } \\
\text { sung as if } \\
\text { addressed to } \\
\text { a female, } \\
\text { keeping in }\end{array}$ \\
\hline
\end{tabular}


Table 15: Sample of Songs.

An analysis of the micro-strategies employed in translating idioms yields some results. The fansubbed version employs SL oriented strategies, i.e. direct translation specifically by $97.6 \%$, almost the whole three songs with a single example of omitted item. This is due to the fact that the fansubber is quite keen to preserve the connotative meanings of the stanzas, without giving much heed to the aesthetic technicalities of rhymed discourse.

\begin{tabular}{|c|c|c|c|}
\hline Strategy & $\begin{array}{l}\text { Fansubbed } \\
\text { Version }\end{array}$ & $\begin{array}{l}\text { Colloquial Arabic } \\
\text { Dubbed Version }\end{array}$ & $\begin{array}{l}\text { MSA Dubbed } \\
\text { Version }\end{array}$ \\
\hline SL Oriented & $97.6 \%$ & $26.18 \%$ & $52.37 \%$ \\
\hline \multirow{6}{*}{$\begin{array}{l}\text { Specification } \\
\text { Explicitation } \\
\text { Addition } \\
\text { Direct } \\
\text { Translation } \\
\text { Calque } \\
\text { Shifted }\end{array}$} & $11.9 \%$ & $4.76 \%$ & $0 \%$ \\
\hline & $0 \%$ & $0 \%$ & $0 \%$ \\
\hline & $11.9 \%$ & $4.76 \%$ & $0 \%$ \\
\hline & $85.7 \%$ & $21.42 \%$ & $52.37 \%$ \\
\hline & $76.19 \%$ & $19.04 \%$ & $28.57 \%$ \\
\hline & $9.52 \%$ & $2.38 \%$ & $23.8 \%$ \\
\hline TL Oriented & $2.38 \%$ & $73.78 \%$ & $47.6 \%$ \\
\hline \multirow{3}{*}{$\begin{array}{l}\text { Generalization } \\
\text { Hyponymy } \\
\text { Other }\end{array}$} & $0 \%$ & $0 \%$ & $9.52 \%$ \\
\hline & $0 \%$ & $0 \%$ & $7.14 \%$ \\
\hline & $0 \%$ & $0 \%$ & $2.38 \%$ \\
\hline \multirow{7}{*}{$\begin{array}{l}\text { Substitution } \\
\text { Cultural } \\
\text { Transcultural } \\
\text { Paraphrase } \\
\text { Sense } \\
\text { Transfer } \\
\text { Situational } \\
\text { Omission }\end{array}$} & $0 \%$ & $61.88 \%$ & $26.18 \%$ \\
\hline & $0 \%$ & $16.66 \%$ & $0 \%$ \\
\hline & $0 \%$ & $16.66 \%$ & $0 \%$ \\
\hline & $0 \%$ & $45.22 \%$ & $26.18 \%$ \\
\hline & $0 \%$ & $23.8 \%$ & $11.9 \%$ \\
\hline & $0 \%$ & $21.42 \%$ & $14.28 \%$ \\
\hline & $2.38 \%$ & $11.9 \%$ & $11.9 \%$ \\
\hline
\end{tabular}

Table 16: Statistics of Songs.

The Colloquial Arabic dubber employs SL oriented strategies with a limited percentage of $26.18 \%$. While, on the other hand, TL oriented strategies are employed with a percentage of $73.78 \%$, with $23.8 \%$ of them sense transfer strategy in which he opts for changing the ST lexical item so as to keep the rhymed scheme of the song, like in song 2; "I was living 
the life" "فونت " " iلت زمانسى، كنت فونت" is an Colloquial Arabic expression indicating a fellow living a lavished life. Besides, it rhymes with "كنت"

The MSA dubber employs SL and TL oriented strategies with nearly balanced percentages of $52.38 \%$ and $47.6 \%$. He makes use of both strategies so as to achieve equilibrium between keeping the semantic, narrative elements, and the rhymed, musical qualities in the songs. Such balance results in a rather artificial, fabricated spirit that marred the TL songs, like in song 3 ; "Out amongst the stars I sail, way beyond the

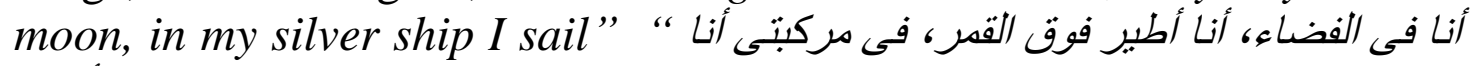
('أطبير”.'.

\subsubsection{Puns}

Puns are considered by Chiaro fuzzy areas that entail a lot of translational manipulation. The following examples are a sample of the comparative analysis of puns in the three versions:

ST Context: A) The toys think that Woody is guilty of throwing Buzz from the Window.

SL Item: 1) Let's string him up by his pull string.

\begin{tabular}{|c|c|c|}
\hline Fansubbed Version & $\begin{array}{l}\text { Colloquial Arabic } \\
\text { Dubbed Version }\end{array}$ & $\begin{array}{c}\text { MSA Dubbed } \\
\text { Version }\end{array}$ \\
\hline ـ لنربطه بخبطه. & ـ ـ كتفوه يا رجالة. & ـ علقوه بسلسلة تشغبله. \\
\hline $\begin{array}{l}\text { A direct calque } \\
\text { strategy that conveys } \\
\text { the meaning accurately } \\
\text { and aptly, however, the } \\
\text { pun in the SL script is } \\
\text { not transferred in the } \\
\text { TL one. }\end{array}$ & $\begin{array}{l}\text { A sense transfer } \\
\text { strategy employing } \\
\text { lexical items like "كتفوه" " } " \text { that is } \\
\text { like " "addressing terms } \\
\text { quite a cultural cliché, } \\
\text { explaining to the TL } \\
\text { audience the intended } \\
\text { ST meaning of } \\
\text { strangling Woody. }\end{array}$ & $\begin{array}{l}\text { A direct shifted } \\
\text { strategy that rather } \\
\text { reflects the meaning of } \\
\text { the pun in the SL } \\
\text { script, but it does not } \\
\text { retain the word play in } \\
\text { "string "and "pull } \\
\text { string". }\end{array}$ \\
\hline
\end{tabular}

B) Woody is mocking Buzz for believing that the blinking button of light on his wrist is a real fatal laser.

2) If anyone attacks us we can blink 'em to death.

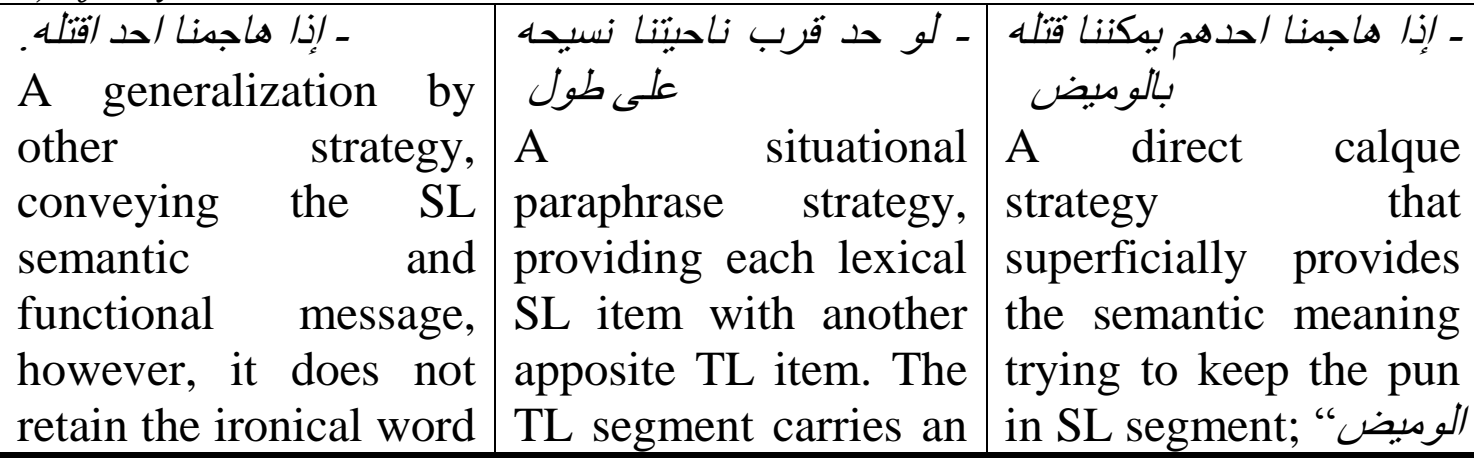




\section{Rania Abdel Baky Allam}

play in "death" "by" ironical hue as the SL ", "لقنل")"

"blink". one as the beaming The result is apt to a light in Buzz's wrist certain extent. can never melt anything.

Table 17: Sample of Puns.

An analysis of the micro-strategies employed in translating puns proves that the fansubber employs the calque direct translation strategy with $50 \%$, as the prime priority is to convey the intended semantic and contextual meanings. He also chooses TL oriented strategies of generalization and sense transfer, with equal ratios, to attempt to convey both the semantic and aesthetic aspects of the pun.

The Colloquial Arabic dubber tries to provide TL oriented

\begin{tabular}{|c|c|c|c|}
\hline Strategy & $\begin{array}{l}\text { Fansubbed } \\
\text { Version }\end{array}$ & $\begin{array}{c}\text { Colloquial Arabic } \\
\text { Dubbed Version }\end{array}$ & $\begin{array}{l}\text { MSA Dubbed } \\
\text { Version }\end{array}$ \\
\hline SL Oriented & $\mathbf{5 0 \%}$ & $0 \%$ & $100 \%$ \\
\hline \multirow{3}{*}{$\begin{array}{l}\text { Direct } \\
\text { Translation } \\
\text { Calque } \\
\text { Shifted }\end{array}$} & $50 \%$ & $0 \%$ & $100 \%$ \\
\hline & $50 \%$ & $0 \%$ & $50 \%$ \\
\hline & $0 \%$ & $0 \%$ & $50 \%$ \\
\hline TL Oriented & $50 \%$ & $100 \%$ & $0 \%$ \\
\hline \multirow{6}{*}{$\begin{array}{l}\text { Generalizatio } \\
\mathrm{n} \\
\text { Other } \\
\text { Substitution } \\
\text { Cultural }\end{array}$} & $25 \%$ & $0 \%$ & $0 \%$ \\
\hline & $25 \%$ & $0 \%$ & $0 \%$ \\
\hline & $25 \%$ & $100 \%$ & $0 \%$ \\
\hline & $0 \%$ & $25 \%$ & $0 \%$ \\
\hline & $0 \%$ & $25 \%$ & $0 \%$ \\
\hline & $25 \%$ & $75 \%$ & $0 \%$ \\
\hline \multirow{4}{*}{$\begin{array}{l}\text { Transcultural } \\
\text { Paraphrase } \\
\text { Sense } \\
\text { Transfer } \\
\text { Situational } \\
\end{array}$} & $25 \%$ & $50 \%$ & $0 \%$ \\
\hline & $0 \%$ & $25 \%$ & $0 \%$ \\
\hline & & & \\
\hline & & & \\
\hline
\end{tabular}

Table 18: Statistics of Puns.

alternatives for the play words by $100 \%$ TL oriented strategies, namely substitution either by transcultural alternative or by paraphrase, as in; " $a$ special place for you, yeah, like the attic",

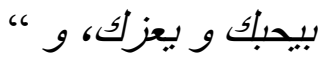
which is a transcultural substitution strategy employed to illuminate the idiomatic meaning of the pun. The extralinguistic fact of putting the unwanted things in the attic in the SL American culture will 
never convey the ironic, paradoxical meaning intended by Mr. Potato Head, since Andy no longer cares about his cowboy toy. Instead, the Colloquial Arabic dubber uses " an adverbial group indicating in the Egyptian culture losing interest in something and putting it aside. On the other hand, the fansubber and the MSA dubber translate this ST segment as follows " نعم مثل الغرفة" respectively. The fansubbed option is a sense transfer that does not reflect the semantic meaning of discard. The MSA choice is one of calque translation that does not conform to the TC, and thus the TC audience will be somehow wondering where the pun lies.

\subsubsection{Idioms}

Idioms, as an element of translation, are considered by Chiaro (2009) a fuzzy area that entails both linguistic and translational handling. The following examples are demonstrated as a sample of the comparative analysis of idiomatic expressions in the three versions:

SL Item: 1) Reach for the sky. (A cliché used to let outlaws leave their arms and lift their hands up).

\begin{tabular}{|c|c|c|}
\hline Fansubbed Version & $\begin{array}{l}\text { Colloquial Arabic } \\
\text { Dubbed Version }\end{array}$ & MSA Dubbed Ve \\
\hline $\begin{array}{l}\text { - اوصل للسداء. } \\
\text { A direct calque exotic } \\
\text { bizarre strategy that } \\
\text { distorts the idiomatic } \\
\text { meaning ultimately. }\end{array}$ & $\begin{array}{l}\text { ـ/رفع /بيلك لفوق. } \\
\text { A transcultural } \\
\text { A substitution } \text { strategy } \\
\text { employing } \\
\text { idiomatic the } \\
\text { term used as a } \\
\text { cultural cliché to stop } \\
\text { outlaws. }\end{array}$ & $\begin{array}{l}\text { A transcultural } \\
\text { A substitution strategy } \\
\text { employing the idiomatic } \\
\text { MSA term used to stop } \\
\text { Mats } \\
\text { outlaws. According the } \\
\text { idiomatic meaning is } \\
\text { appositely transferred in } \\
\text { the TL script. }\end{array}$ \\
\hline \multicolumn{3}{|c|}{ 2) Coast is clear. (Everything is clear and safe). } \\
\hline 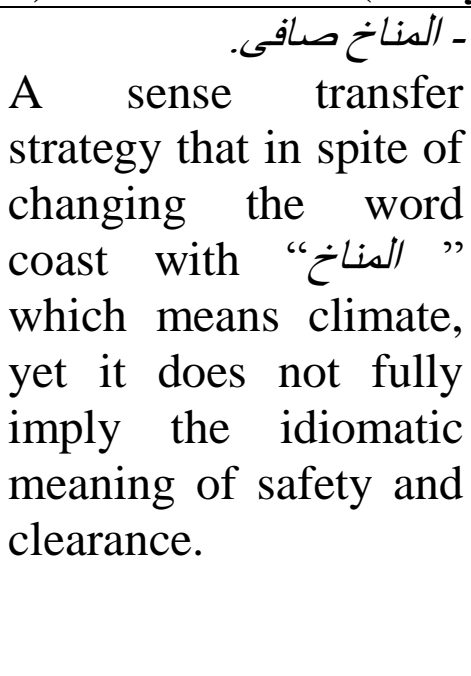 & $\begin{array}{l}\text { A transcultural } \\
\text { substitution strategy } \\
\text { that succeeds in } \\
\text { changing the whole } \\
\text { SL idiom by another } \\
\text { one in the TL, } \\
\text { implying the } \\
\text { idiomatic meaning of } \\
\text { safety and clearance. }\end{array}$ & $\begin{array}{l}\text { A transcultural } \\
\text { A strategy } \\
\text { substitution succeeds in } \\
\text { that st } \\
\text { changing the whole SL } \\
\text { idiom by another one in } \\
\text { the MSA TL, implying } \\
\text { the idiomatic meaning } \\
\text { of safety and clearance, } \\
\text { the same as the } \\
\text { Colloquial Arabic } \\
\text { dubbed version. }\end{array}$ \\
\hline
\end{tabular}


3) Using the same old noodle. (Using one's head in contriving plans and ideas).

- 2 - نستخدم مكرونة قديهة.

A direct calque strategy that results in an exotic, bizarre and literary translation of lexical items without conveying even remotely to the idiomatic intended meaning.

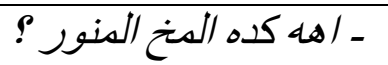
A situational paraphrase strategy, providing an explanatory alternative for the SL aptly and tactfully invoking the same SL effect.

\section{ـ الخطة القدبية ذ/تها؟}

A sense transfer strategy, in which the MSA dubber replaces "noodle" with in which the MSA dubber replaces "noodle" with "الخطة", a translational behavior that elucidates the idiomatic connotative and denotative hues.

Table 19: Sample of Idioms.

An analysis of the micro-strategies employed in translating idioms yields many results. The fansubbed version employs SL oriented strategies by $43.17 \%$, and TL oriented strategies by $56.79 \%$. It seems that he tries to balance between both.

\begin{tabular}{|c|c|c|c|}
\hline Strategy & $\begin{array}{c}\text { Fansubbed } \\
\text { Version }\end{array}$ & $\begin{array}{c}\text { Colloquial } \\
\text { Arabic } \\
\text { Dubbed } \\
\text { Version }\end{array}$ & MSA Dubbed Version \\
\hline SL Oriented & $43.17 \%$ & $13.62 \%$ & $24.99 \%$ \\
\hline \multirow{6}{*}{$\begin{array}{l}\text { Specification } \\
\text { Explicitation } \\
\text { Addition } \\
\text { Direct Translation } \\
\text { Calque } \\
\text { Shifted }\end{array}$} & $0 \%$ & $6.82 \%$ & $2.27 \%$ \\
\hline & $0 \%$ & $4.54 \%$ & $0 \%$ \\
\hline & $0 \%$ & $2.27 \%$ & $2.27 \%$ \\
\hline & $43.17 \%$ & $6.81 \%$ & $22.72 \%$ \\
\hline & $40.9 \%$ & $6.81 \%$ & $9.09 \%$ \\
\hline & $2.27 \%$ & $0 \%$ & $13.63 \%$ \\
\hline TL Oriented & $56.79 \%$ & $86.34 \%$ & $74.97 \%$ \\
\hline \multirow{11}{*}{$\begin{array}{l}\text { Generalization } \\
\text { Hyponymy } \\
\text { Other } \\
\text { Substitution } \\
\text { Cultural } \\
\text { Transcultural } \\
\text { TL Cultural } \\
\text { Paraphrase } \\
\text { Sense Transfer } \\
\text { Situational } \\
\text { Omission }\end{array}$} & $4.54 \%$ & $2.27 \%$ & $4.54 \%$ \\
\hline & $0 \%$ & $2.27 \%$ & $2.27 \%$ \\
\hline & $4.54 \%$ & $0 \%$ & $2.27 \%$ \\
\hline & $38.62 \%$ & $77.26 \%$ & $65.89 \%$ \\
\hline & $6.81 \%$ & $15.9 \%$ & $11.36 \%$ \\
\hline & $4.54 \%$ & $13.63 \%$ & $9.09 \%$ \\
\hline & $2.27 \%$ & $2.27 \%$ & $2.27 \%$ \\
\hline & $31.81 \%$ & $61.36 \%$ & $54.53 \%$ \\
\hline & $29.54 \%$ & $34.09 \%$ & $47.72 \%$ \\
\hline & $2.27 \%$ & $27.27 \%$ & $6.81 \%$ \\
\hline & $13.36 \%$ & $6.81 \%$ & $4.54 \%$ \\
\hline
\end{tabular}

Table 20: Statistics of Idioms. 
For instance, he employs generalization and condensation at the same time to avoid a problematic translational area in a rhymed idiom "Way to go, Idaho!" "عظبم", uttered by the toy pig Hamm hailing the fact that there is a Mrs. Potato Head among Andy's new Christmas gifts, a maneuver that saves the difficult translational situation.

The Colloquial Arabic dubber employs SL oriented strategies with a very limited percentage of $13.62 \%$. TL oriented strategies are employed extensively with a high percentage of $86.34 \%$, and in most examples successfully. In the rhymed idiom; "Way to go, Idaho!" “" "أبوه با عم و هتخلم", Colloquial Arabic dubber resorts to situational paraphrase strategy adding rhyme to it, which is an excellent idiomatic combination invoking the same effect, of the hailing phrase.

The MSA dubber employs SL oriented strategies with a rather limited percentage of $24.99 \%$. He makes use of TL oriented strategies with $74.97 \%$. He, in most cases, employs them tactfully to convey the meaning. In the previous example, he translates it as “ كم أنت محظوظ با صديقى". Although the expression is not TL idiomatic one, it exhibits the meaning quite aptly.

\subsubsection{Humor}

Antonini (2005) thinks that translating verbally expressed humor "is one of the most difficult challenges that a translator has to face in her work; when, in addition, the audiovisual translator has to comply with the limits imposed by the subtitling process". Such difficult task has to result in translational manipulation that evokes the same funny effect of the SL segments. The following examples are a sample of the comparative analysis of humor in the three versions:

ST Context: Woody is reminding the toys that they have to pick another toy to stick with while they are moving to the new house. Mr. Potato Head loosens his hand and holds it by the other one, joking that, they have to hold hands, while he literarily is holding his loosened hand.

\begin{tabular}{|c|c|c|}
\hline \multicolumn{3}{|c|}{ SL item: Do we have to hold hands. } \\
\hline Fansubbed Version & $\begin{array}{c}\text { Colloquial Arabic Dubbed } \\
\text { Version }\end{array}$ & $\begin{array}{l}\text { MSA Dubbed } \\
\text { Version }\end{array}$ \\
\hline ـ هل يجب أن نمسك أيبينا؟ & بعىى نمسك فى ايدين بعض. & ـ علينا أن نحمل أبيد. \\
\hline $\begin{array}{l}\text { A direct shifted } \\
\text { strategy that rather } \\
\text { reflects the funny } \\
\text { meaning intended by }\end{array}$ & $\begin{array}{l}\text { A direct shifted strategy, } \\
\text { however, it fails to invoke the } \\
\text { same funny effect as the intended } \\
\text { joke is that they are holding }\end{array}$ & $\begin{array}{l}\text { A direct calque } \\
\text { strategy that reflects } \\
\text { the funny meaning } \\
\text { intended by Mr. }\end{array}$ \\
\hline $\begin{array}{l}\text { Mr. Potato Head's } \\
\text { verbal as well as } \\
\text { visual joke. }\end{array}$ & $\begin{array}{l}\text { actual hands at the moment of } \\
\text { speaking, when Mr. Potato } \\
\text { Head's verbal is literarily } \\
\text { catching his loosen hand. }\end{array}$ & $\begin{array}{l}\text { Potato Head, who is } \\
\text { holding an actual } \\
\text { hand. }\end{array}$ \\
\hline
\end{tabular}

Table 21: Sample of Humor. 


\begin{tabular}{|c|c|c|c|}
\hline \multicolumn{4}{|c|}{ Rania Abdel Baky Allam } \\
\hline Strategy & $\begin{array}{c}\text { Fansubbed } \\
\text { Version }\end{array}$ & $\begin{array}{l}\text { Colloquial } \\
\text { Arabic } \\
\text { Dubbed } \\
\text { Version }\end{array}$ & $\begin{array}{c}\text { MSA } \\
\text { Dubbed } \\
\text { Version }\end{array}$ \\
\hline SL Oriented & $71.42 \%$ & $71.42 \%$ & $85.71 \%$ \\
\hline \multirow{5}{*}{$\begin{array}{l}\text { Specification } \\
\text { Explicitation } \\
\text { Direct Translation } \\
\text { Calque } \\
\text { Shifted }\end{array}$} & $14.28 \%$ & $0 \%$ & $0 \%$ \\
\hline & $14.28 \%$ & $0 \%$ & $0 \%$ \\
\hline & $56.56 \%$ & $71.42 \%$ & $85.71 \%$ \\
\hline & $42.85 \%$ & $57.14 \%$ & $57.14 \%$ \\
\hline & $14.28 \%$ & $14.28 \%$ & $28.57 \%$ \\
\hline TL Oriented & $28.56 \%$ & $28.56 \%$ & $14.28 \%$ \\
\hline \multirow{4}{*}{$\begin{array}{l}\text { Substitution } \\
\text { Paraphrase } \\
\text { Sense Transfer } \\
\text { Situational }\end{array}$} & $28.56 \%$ & $28.56 \%$ & $14.28 \%$ \\
\hline & $28.56 \%$ & $28.56 \%$ & $14.28 \%$ \\
\hline & $28.56 \%$ & $14.28 \%$ & $14.28 \%$ \\
\hline & $0 \%$ & $14.28 \%$ & $0 \%$ \\
\hline
\end{tabular}

Table 22: Statistics of Humor.

The analysis of translating the humor dimension in the three versions proves that the dominantly employed strategies are the SL oriented ones. Both the fansubbed and the Colloquial Arabic dubbed versions use SL oriented strategies by $71.41 \%$, evoking the same funny verbal as well as non-verbal effect of the humor in the TT. Besides, the MSA version employs SL oriented strategies with a close percent of $85.71 \%$, conveying the same humorous effect.

It can be detected that the SL oriented strategies are quite effective in evoking humorous effects. Trying to find TL alternatives that fit semantically, contextually and culturally in the TC so as to stimulate the same funny effect is not always a feasible process.

Nonetheless, there is an example that proves a dexterous translation manipulation on the part of the three translators in the present study. Buzz's hand is broken after he tries to fly from over the banister, refusing to believe that he is just an action figure, he is shocked, depressed and dizzy from the fall and holds his broken hand playing with it. When Woody is trying to convince the toys from over the window that he is innocent of killing Buzz, he urges him to get up to show himself and give him a hand in proving his innocence to them. Woody says "Will you get up here and give me a hand?" Buzz ironically, being unstable, throws the broken hand he holds to Woody. In the fansubbed version it is translated as "باز تعالى هنا أعطنى بيك للمساعدة", a specification by explicitation strategy which illuminates the intended meaning that coincides with the visual humor. In the Colloquial Arabic dubbed version, it is translated as " باز ايلك 
a substitution by situational paraphrase strategy that well conveys the joke. The MSA choice is one of shifted direct translation that conforms to the SL intended funny meaning, it is translated as " باز أعطنى يبك و انهض يا "رجل but does not reflect the idiomatic meaning of help in the term give a hand.

\subsection{Syntactic Code}

Such code utilizes syntactic constructions and arrangements to tackle technicalities of AVT and handle the problematic areas of excessive length, isochrony etc. Each translated version of the movie under study tackles the syntactic variations and structures, as can be exemplified in the following:

\begin{tabular}{|c|c|c|}
\hline \multicolumn{3}{|c|}{$\begin{array}{l}\text { SL Item: } \\
\text { 1) Rex: His birthday's not 'till next week. }\end{array}$} \\
\hline Fansubbed Version & $\begin{array}{l}\text { Colloquial Arabic } \\
\text { Dubbed Version }\end{array}$ & $\begin{array}{l}\text { MSA Dubbed } \\
\text { Version }\end{array}$ \\
\hline - عبي مبلاده لبس الأسبوع & - عبا مبلاده الأسبوع اللى & Omitted. \\
\hline \multicolumn{3}{|c|}{ 2) Oh, ya, Big lizard. It is an insult phrase. } \\
\hline - إنها سحلية كبيرة. & ـ ـ كده يا برص. & ـ أبتها السحلبة الكبيرة. \\
\hline \multicolumn{3}{|c|}{ 3) Keep out of reach of children. } \\
\hline ـ ابعدوها عن الأطفال. & - بحفظ بعبل عن أبلى الأطفال. & ـ ابقه بعبل/ عن الأولاد. \\
\hline
\end{tabular}

Table 23: Sample of Syntactic Code.

The syntactic structures are intended in the ST to convey a certain semantic and syntactic function. However, they are manipulated differently in the three translated versions for various reasons, yet they have nothing to do with translational manipulation for AVT constrains. In example 1, the fansubbing translator employs a direct, shifted translation strategy, omitting the adverbial group of time "till", mitigating the whole meaning as if Rex is negating the phrase that Andy's birthday is next week, not confirming it as implied by the ST segment. In the Colloquial Arabic dubbed version the ST segment is transferred by a direct, shifted translation strategy, yet conveying by using the indicative phrase, the meaning intended in the ST. As for the MSA dubbed version the ST segment is omitted, as deemed insignificant by the translator, while in fact it conveys an exclamatory, intended meaning. 
Rania Abdel Baky Allam

In example 2, the fansubbing translator employs an indicative

\begin{tabular}{|c|c|c|c|}
\hline Strategy & $\begin{array}{l}\text { Fansubbed } \\
\text { Version }\end{array}$ & $\begin{array}{l}\text { Colloquial Arabic } \\
\text { Dubbed Version }\end{array}$ & $\begin{array}{l}\text { MSA Dubbed } \\
\text { Version }\end{array}$ \\
\hline SL Oriented & $75 \%$ & $56.25 \%$ & $87.25 \%$ \\
\hline \multirow{6}{*}{$\begin{array}{l}\text { Specification } \\
\text { Explicitation } \\
\text { Addition } \\
\text { Direct } \\
\text { Translation } \\
\text { Calque } \\
\text { Shifted }\end{array}$} & $0 \%$ & $6.25 \%$ & $6.25 \%$ \\
\hline & $0 \%$ & $6.25 \%$ & $0 \%$ \\
\hline & $0 \%$ & $0 \%$ & $6.25 \%$ \\
\hline & $75 \%$ & $50 \%$ & $81 \%$ \\
\hline & $43.75 \%$ & $18.75 \%$ & $43.75 \%$ \\
\hline & $31.25 \%$ & $31.25 \%$ & $37.25 \%$ \\
\hline TL Oriented & $25 \%$ & $43.75 \%$ & $12.5 \%$ \\
\hline \multirow{3}{*}{$\begin{array}{l}\text { Substitution } \\
\text { Cultural }\end{array}$} & $25 \%$ & $43.75 \%$ & $6.25 \%$ \\
\hline & $0 \%$ & $18.75 \%$ & $0 \%$ \\
\hline & $0 \%$ & $18.75 \%$ & $0 \%$ \\
\hline \multirow{5}{*}{$\begin{array}{l}\text { Transcultural } \\
\text { TL } \\
\text { Cultural } \\
\text { Paraphrase } \\
\text { Sense } \\
\text { Transfer } \\
\text { Situational } \\
\text { Omission }\end{array}$} & $0 \%$ & $0 \%$ & $0 \%$ \\
\hline & $25 \%$ & $25 \%$ & $6.25 \%$ \\
\hline & $25 \%$ & $12.5 \%$ & $0 \%$ \\
\hline & $0 \%$ & $12.5 \%$ & $6.25 \%$ \\
\hline & $0 \%$ & $0 \%$ & $6.25 \%$ \\
\hline
\end{tabular}

Table 24: Statistics of Syntactic Code.

structure omitting the illocutionary force purpose of insult. A direct, shifted translation strategy is employed. This reflects a failure in comprehending the semantic and syntactic significance of the ST segment. In the Colloquial Arabic dubbed version the ST segment is transferred by a paraphrase sense transfer translation strategy. It employs a cultural substitution of a lexicon used as an insult "برص". As for the MSA dubbed version the ST segment is translated directly as a calque conveying the intended meaning.

In example 3, both the fansubbing and the MSA dubbing translators employ a calque syntactic structure that yields a very exotic result. This is done with no obvious reasons, as the space on screen and lip synchronization do not require such strange, unfamiliar TT segments. On the other hand, the Colloquial Arabic dubbing translator again opts for a familiar, meaningful unmarked cultural substitution strategy, resulting in a TT segment quite acceptable and common in the TC, to the extent of being a well-known cliché inscribed on most of the hazardous products. 


\section{Findings}

The previous analyses of the musical, sound arrangement, iconographic, mobility linguistic and syntactic codes illustrate certain points concerning the micro strategies adopted in the audio visual translation of the three versions. Such points can be pinned down as follows:

- In the fansubbed version the SL strategies are adopted with a high percentage of $74.65 \%$, for all the analyzed elements, while the TL strategies are employed with a limited percentage of $25.33 \%$. This signifies that, the amateur fansubber is more loyal, to the SL script dealing with faithful, semantic and opaque transference of the SL content and form with a partial, marginal interference, to alter or manipulate any translational difficulty.

\begin{tabular}{|c|c|c|c|}
\hline Strategy & $\begin{array}{c}\text { Fansubbed } \\
\text { Version }\end{array}$ & $\begin{array}{l}\text { Colloquial Arabic } \\
\text { Dubbed Version }\end{array}$ & $\begin{array}{l}\text { MSA Dubbed } \\
\text { Version }\end{array}$ \\
\hline SL Oriented & $74.65 \%$ & $\mathbf{3 4 . 7 1 \%}$ & $65.32 \%$ \\
\hline \multirow{9}{*}{$\begin{array}{l}\text { Retention } \\
\text { Complete } \\
\text { Retention } \\
\text { Adjusted } \\
\text { Specification } \\
\text { Explicitation } \\
\text { Addition } \\
\text { Direct Translation } \\
\text { Calque } \\
\text { Shifted }\end{array}$} & $10.85 \%$ & $4.74 \%$ & $13.11 \%$ \\
\hline & $10.42 \%$ & $4.67 \%$ & $10.8 \%$ \\
\hline & $0.43 \%$ & $0.06 \%$ & $2.13 \%$ \\
\hline & $3.35 \%$ & $2.86 \%$ & $0.96 \%$ \\
\hline & $2.27 \%$ & $1.29 \%$ & $0.19 \%$ \\
\hline & $1.08 \%$ & $1.57 \%$ & $0.77 \%$ \\
\hline & $60.4 \%$ & $27.11 \%$ & $44.24 \%$ \\
\hline & $50.1 \%$ & $20.82 \%$ & $33.48 \%$ \\
\hline & $10.36 \%$ & $6.29 \%$ & $17.75 \%$ \\
\hline TL Oriented & $25.33 \%$ & $65.28 \%$ & $34.64 \%$ \\
\hline \multirow{12}{*}{$\begin{array}{l}\text { Generalization } \\
\text { Hyponymy } \\
\text { Other } \\
\text { Substitution } \\
\text { Cultural } \\
\text { Transcultural } \\
\text { TL Cultural } \\
\text { Paraphrase } \\
\text { Sense Transfer } \\
\text { Situational } \\
\text { Omission } \\
\text { Official Equivalent }\end{array}$} & $6.17 \%$ & $3.68 \%$ & $4.95 \%$ \\
\hline & $2.68 \%$ & $2.7 \%$ & $2.62 \%$ \\
\hline & $3.54 \%$ & $0.98 \%$ & $1.87 \%$ \\
\hline & $14.91 \%$ & $57.45 \%$ & $23.42 \%$ \\
\hline & $0.68 \%$ & $17.47 \%$ & $2.75 \%$ \\
\hline & $0.41 \%$ & $16.54 \%$ & $1.75 \%$ \\
\hline & $0.27 \%$ & $0.94 \%$ & $1 \%$ \\
\hline & $14.23 \%$ & $40 \%$ & $20.58 \%$ \\
\hline & $13.78 \%$ & $23.14 \%$ & $15.51 \%$ \\
\hline & $0.64 \%$ & $16.84 \%$ & $6.05 \%$ \\
\hline & $4.22 \%$ & $3.79 \%$ & $4.64 \%$ \\
\hline & $0 \%$ & $0.36 \%$ & $0.36 \%$ \\
\hline
\end{tabular}

Table 25: Collective Statistics.

Besides, he resorts to the most unswerving SL strategy, namely retention with $10.85 \%, 10.42 \%$ for the complete retention strategy only. He transfers the SL items as they are, with no deviation whatsoever. Direct 
translation is employed in $60 \%$ of the SL strategies; a percentage of $50.1 \%$ of the translational decisions is allocated for calque (one of the very literal SL transfer) choices, and $10.36 \%$ only for the shifted ones. Even the SL oriented strategies that need some addition or explanation, like specification, are used on a very limited scale $3.35 \%$.

On the other hand, the fansubber resorts to the TL oriented strategies, when he has no other choice except explaining or paraphrasing the SL segment so as to be readable. This is done with a minor percentage of $14.23 \%$ for sense transfer, and $13.78 \%$ for the situational paraphrase. He provides cultural substitution, in some rare examples, which meagerly reaches $0.68 \%$. Such policies of strict adhering to the SL script and very frequently abandoning the TL and its linguistic, functional and cultural hues lead to erroneous translations, misapprehension and distorted meanings, like in; moving buddy رفيق متحرك , لماذا خرجت , will you quit moving around, مشتروتيرف Astroturf, مشتاق قليلا Give me five أعطنى مهلة. All such SL segments are either mistakenly interpreted or literarily translated in an exotic faulty manner.

- In the dubbed Arabic Colloquial Arabic version the TL strategies are adopted at the high percentage of $65.28 \%$, for all the analyzed elements, while the SL strategies are employed in the rather minor percentage of $34.71 \%$. This signifies that the Colloquial Arabic dubber is loyal mainly to the TL and the TC so as to weave the translated product within the fabric of the TL, and to familiarize its elements to the viewers so as to appear originally written in the TL. Furthermore, the TL oriented strategy that renders the TL an adaptation more than a translation is that of substitution $57.45 \%$ either by cultural substitution $17.47 \%$ or paraphrase $40 \%$ which is quite a high percentage. The Colloquial Arabic dubber substitutes the elements of the SL with cultural or paraphrased equivalents of the TL, especially in the problematic fuzzy areas and CSRs. He adopts SL oriented strategies at the rather minor percentage of $27.11 \%$ for the direct translation with its two types. He resorts to the explicitation and addition specification strategies with $2.82 \%$, two SL strategies that entails some manipulation. The retention strategy of keeping the ST segments as they are in spirit and letters is used mainly in the translation of names with $4.47 \%$ only. This results in an adapted product which retains the spirit, hue, culture and flavor of the TL, so the TC audience, namely cartoon viewers (mainly from children), would feel at home with such an adapted audiovisual product. In addition, it results also in a well interpreted, rarely erroneous TL with exceptional cases of faulty translations, like in; cargo area نقطقة التفريغ Star Commander, تقري اخبارى Nirvana الاستر/حة. Although such examples are not accurate TL 
equivalents, they are not considered utterly erroneous or misapprehended. They can be considered as an overcontextualized adaptation.

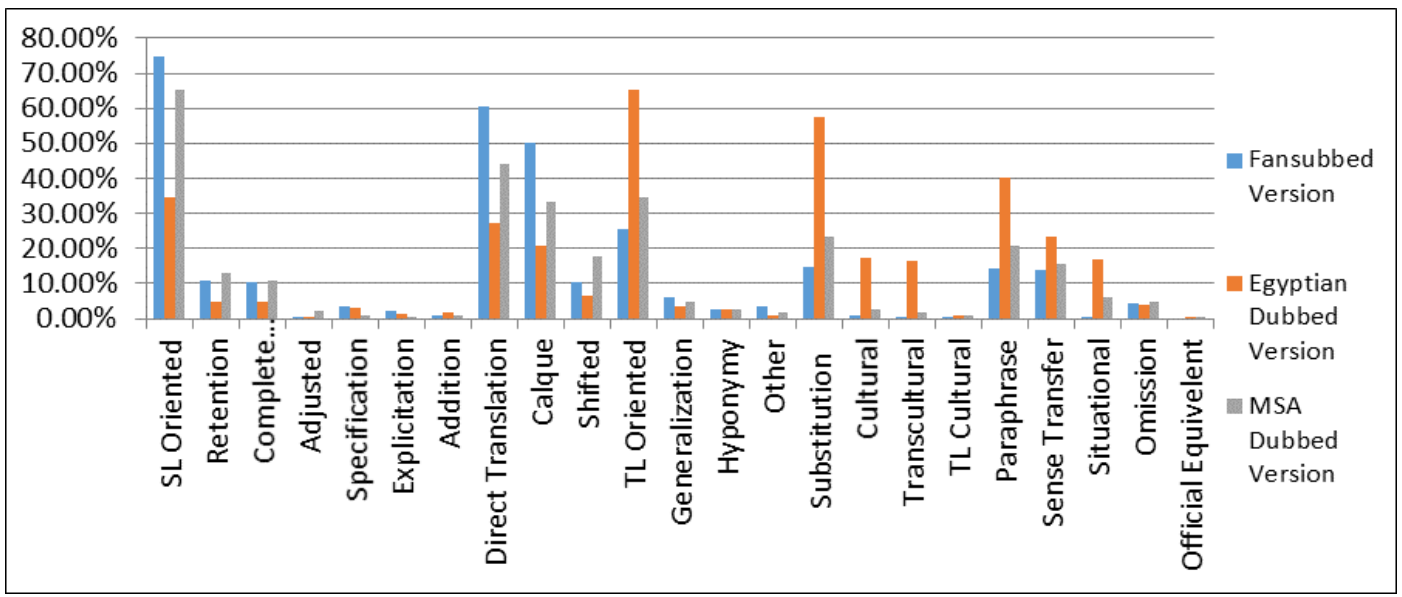

Figure 4: Comparative Chart of SL and TL Oriented Strategies.

- In the MSA version the percentages are nearly the opposite of the Colloquial Arabic dubbed version. The SL oriented strategies are adopted with the percentage of $65.32 \%$, while the TL oriented strategies are employed with $34.64 \%$. The MSA dubber adheres more to the SL script retaining more than half of its features. However, the most conspicuous feature in the SL strategies employed is the rather remarkable percentage of the retention strategy $13.11 \%$, in which $10.8 \%$ of them are complete retention examples. This is quite a notable percentage for a supposedly professional dubber, who resorts to exact transference of the SL even in letters, like in; Mission Log المهمة لوج , Nirvana نيرفانا .The TL oriented strategy principally pivots around sense transfer strategy by $15.51 \%$ which is quite remarkable in comparison with the situational paraphrase and the cultural substitutions by $6.05 \%$ and $2.75 \%$ respectively. This indicates that the MSA dubber does not attempt to find cultural substituting elements familiar to the TC recipient. He is more loyal to the foreign SL strategies, with nearly half $44.24 \%$ of the strategies adopted in the selected examples are translated directly or literally. Nevertheless, the MSA dubber differs from the fansubber in being more flexible in adjusting the translated SL segment to the norms of the TL, so he does some shifts employing the shifted direct translation by $17.75 \%$ and the adjusted retention strategy with the highest percentage of the three versions with $2.13 \%$. This proves some expertise and manipulation, yet with propensity to the SL norms and spirit. Accordingly, he produces less flawed TL translational decisions, though some flaws do exist also, like

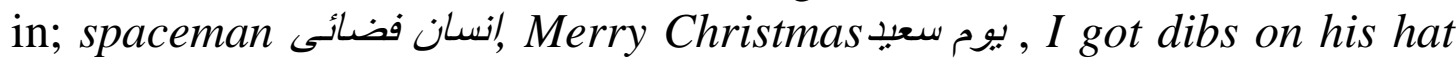
(idiomatic expression means he admires) فلنجدع المال فحى قبعته 


\section{Conclusion}

It can be inferred from the present study that the three audiovisual versions under study display great discrepancies concerning micro translational strategies adopted in each of them. Consequently, they exhibit great discrepancy in the macro or mega translational strategies, as the two dubbed versions have certain acoustic, visual and textual technicalities that differ from those of the fansubbed version. This difference within the translation medium and the difference among the translators themselves (being presumably professional in the dubbed varieties of Arabic and amateurs in the fansubbed) result in some discrepancies.

As regards to musical, sound arrangement and mobility codes, the Colloquial Arabic dubbed version is the most professional of the three. It displays the codes in a proficient manner, as illustrated above. The fansubbed and the MSA dubbed ones merely transfer the verbal data without much concern given to the stipulations of such codes. Nonetheless, in the iconographic code the three versions discarded the translation of such visual material.

Furthermore, the quantitative and qualitative analyses of the fansubbed version reveal that it tends to be quite foreignized. With three quarters of the micro translational strategies as SL oriented, the fansubber gets the target audience as close and familiar as possible to the SL script and to its values, culture and milieu, by adopting direct, literal, semantic and sometimes word for word translation. Nonetheless, in the process, the fansubbed sacrificed a great deal of precision. Erroneous semantic or syntactic transference, failure in hearing and minimal comprehension of utterances amount to $13.29 \%$. This is a pretty notable percentage. Moreover, the fansubber breaks many syntactic rules of the Arabic grammar. The object never shows the accidence or inflection of nunation and some imperative forms of verb inflection. This is in addition to some orthographic and spelling mistakes in the fansubbed lines. All such aspects prove that the fansubber lacks some professional experience and translational and technical expertise.

The qualitative and quantitative analyses of the Colloquial Arabic dubbed version demonstrate that this version tends to be quite domesticated. With more than half of the micro translational strategies as TL oriented, the Colloquial Arabic dubber gets the foreign SL script in the vicinity of the TL realm, and thus to the target audience as well. The TL dubbed product is in harmony with the TL preconceptions and preferences, to the extent of substituting the SL items with TL ones with $57.45 \%$. This dubbed version of the Toy Storyl seems as if it is originally written in this Arabic variety. Besides, being dubbed under the 
supervision of a professional company like Walt Disney, the percentage of translational inaccuracy or flawed decisions is quite sparse, only $3.44 \%$, nevertheless, with none of the examples being bizarre, odd or exotic. They are all within the fabric of the TL script. This proves the professional experience and translational and technical expertise of the translators.

The quantitative and qualitative analysis of the MSA dubbed version demonstrates that it tends to be foreignized. With more than half of the micro translational strategies, as SL oriented, the MSA dubber is liable to get the target audience closer to the SL script and to its values, culture and milieu, by adopting direct, literal translation with $44.24 \%$. He opts for substituting the SL items with TL ones with $23.42 \%$, a percentage near the quarter. This lessened the faulty semantic or syntactic transference. Nonetheless, failure in hearing, on the one hand, and minimal comprehension of utterances, on the other, exist by $8.54 \%$. This is a distinguished percentage, putting into consideration that Jeem $\mathrm{T} . \mathrm{V}$ is a professional company for dubbing many cartoons of Disney productions. However, professional experience and translational and technical expertise appear in the attempt to balance between the SL and TL norms.

Eventually, it can be said that there are noteworthy discrepancies among the three versions of the movie under study. Each audiovisual translator opts for a certain mega strategy, and thus employs certain micro strategies. Furthermore, Pedersen's model proves to be valid as a tool of analyzing, not only the CSRs, but also it can be stretched to cover all the linguistic aspects in the SL script. The combination of the two models of Chaume (2004) and Chiaro (2009) encompassing the audiovisual codes of the whole three versions of the movie, proves to be quite valid. Such multi model design is recommended to be employed in future studies, covering some other areas of research. 


\section{References}

Al-Alami, B. N. (2006). Dubbing Timon \& Pumbaa cartoon into Egyptian Arabic (master's thesis). American University of Sharjah, Sharjah, United Arab Emirates. Retrieved from https://dspace.aus.edu/ xmlui/.../29.232-2011.12\%20Budor\%20Al\%20 Alami.pdf?.

Al-Jabri, S. M. (2017). Rendering of culture-bound references from English into Arabic: Subtitling and dubbing of personal names in children's cartoons. Journal of Arabic and Human Sciences. Qassim University, 10(3), 17-42. Retrieved from publications.qu.edu.sa/ojs/ index.php/arab/article/download/1486/1389

Alkadi, T. (2010). Issues in Subtitling and Dubbing of English-Language Films into Arabic: Problems and Solutions (doctoral dissertation) Durham University, Durham, United Kingdom. Retrieved from http://etheses.dur.ac.uk/326/1/Final_TammamAlkadi_Thesis.pdf?DDD3 $\underline{6+}$

Antonini, R. (2005). The Perception of subtitled humour in Italy: Humor 18(2), 209-225. Retrieved from http://academic.csuohio.edu/ kneuendorf/frames/subtitling/Antonini.2005.pdf

Bagheri, M., \& Nemati, A. (2014). On the Translation Strategies of Movie Dubbing and Subtitling: A Frequency Analysis on Explicitation in Translation. Linguistics and Literature Studies, 2(3), 86-91. Retrieved from http://www.hrpub.org/download/20140205/LLS3-19301788.pdf

Bartrina, F., \& Espasa, E. (2005). Audiovisual translation. In M. Tennent (Ed.), Training for the New Millennium: Pedagogies for Translation and Interpreting, (pp. 83-100). Philadelphia: John Benjamins.

Catford, J. C. (1965). A Linguistic Theory of Translation: An Essay in Applied Linguistics. Oxford, Oxford University Press.

Chiaro, D. (2009). Issues in audiovisual translation. In J. Munday (Ed.), The Routledge Companion to Translation Studies, (pp. 141-165). London: Routedge.

Chaume, F. (2004). Film studies and translation studies: Two disciplines at stake in audiovisual translation. Meta: Translators' Journal, 49(1), 1224. Retrieved from https://www.erudit.org/en/journals/meta/2004-v49n1-meta733/009016ar.pdf

Delabastita, D. (1996). Introduction. The Translator, 2(2), 127-139. Retrieved from 13556509.1996.10798970

http://www.tandfonline.com/doi/abs/10.1080/

De Linde, Z., \& Kay, N. (1999). Processing subtitles and film images: Hearing vs. deaf viewers. The Translator, 5(1), 45-60. Retrieved from http://www.tandfonline.com/doi/abs/10.1080/13556509.1999.10799033

Denton, J., \& Ciampi, D. (2012). A New development in audiovisual translation studies: Focus on target audience perception. LEA - Lingue e Letterature d'Oriente e d'Occidente, 1(1), 399-422. Retrieved from file:///C:/Users/rona/Downloads/12469-22784-1-PB\%20(6).pdf 
Díaz-Cintas, J. (2012). Subtitling theory, practice and research. In C. Millán and F. Bartrina (Eds.), The Routledge Handbook of Translation Studies, (pp. 273-287). London. Routledge.

Díaz-Cintas, J., \& Anderman, G. (2009). Introduction. In J. Díaz-Cintas \& G. Anderman (Eds.), Audiovisual Translation: Language Transfer on Screen, (pp. 1-17). Basingstoke: Palgrave Macmillan.

Eggleston, R. (Director). (1995). Toy Story 1 [Video file]. United States: Walt Disney Pictures/Pixar Animation Studios. Egyptian Colloquial Arabic Dubbed Version Retrieved July 4, 2017, from https://www.dailymotion.com/video/x3k37y5

Eggleston, R. (Director). (1995). Toy Story 1 [Video file]. United States: Walt Disney Pictures/Pixar Animation Studios. Fansubbed Version Retrieved July 8, 2017, from https://egy.best/movie/toy-story-1995/

Eggleston, R. (Director). (1995). Toy Story 1 [Video file]. United States: Walt Disney Pictures/Pixar Animation Studios. Modern Standard Arabic Dubbed Version Retrieved July 15, 2017, from http://www.stardima.com/watch/watch.php?vid=42123ad77

Eldalees, H. A., Al-Adwan, A., \& Yahiaoui, R. (2017). Fansubbing in the Arab world: Modus Operandi and prospects. Arab World English Journal for Translation and Literary Studies AWEJ, 1(1), 48-64. Retrieved from http://awej-tls.org/wp-content/uploads/2017/03/4.pdf

Ferguson, C. A. (1959). Diglossia. Word 15, 325-340. Retrieved from http://www.mapageweb.umontreal.ca/tuitekj/cours/2611pdf/FergusonDiglossia.pdf

Fernandes, L. (2006). Translation of names in children's fantasy literature: Bringing the young reader into play. New Voices in Translation Studies, 2, 44-57. Retrieved from https://www.researchgate.net/ publication/237246131_Translation_of_Names_in_Children's_Fantasy Literature Bringing the Young Reader into Play $\mathrm{i}$

Gamal, M. (2009). Foreign movies in Egypt: subtitling, dubbing and adaptation. In A. Goldstein \& B. Golubovic, Foreign Language movies: Dubbing vs. Subtitling, (pp. 1-16). Hamburg: Verlag Dr.Kovač. Retrieved from https://www.academia.edu/7668074/ Foreign movies in Egypt subtitling dubbing and adaptation

Gambier, Y. (2009). Challenges in research on audiovisual translation. In A. Pym \& A. Perekrestenko, (Eds.), Translation Research Projects 2, (pp. 17-25). Tarragona: Intercultural Studies Group. Retrieved from http://www.intercultural.urv.cat/media/upload/domain_317/arxius/TP2/ TRP 2 may 3.pdf

House, J. (1977). A Model for Translation Quality Assessment, Tübingen, Gunter Narr Verlag.

Jabbari, M. J. (2012). Diglossia in Arabic: A Comparative study of the modern standard Arabic and Egyptian colloquial Arabic. Global Journal of Human Social Science, XII, VIII(I), 23-36. Retrieved from 
https://globaljournals.org/GJHSS_Volume12/E_Journal_GJHSS_Vol_Is sue_8_May_2012.pdf

Jaleniauskiené, E., \& Čičelyté, V. (2009). The Strategies for translating proper names in children's literature. Kalbu Studijos 15, 31-42. Retrieved from https://www.researchgate.net/publication/

228653802_The_Strategies_for_Translating_Proper_Names_in_Childre n's Literature

Khalaf, A. S., \& Rashid, S. M. (2012). Attenuating obscenity of swearwords in the amateur subtitling of English movies into Arabic. Arab World English Journal (AWEJ), 7(1), 295 - 309. Retrieved from file:///C:/Users/rona/Downloads/AWEJV7N1295309\%20(1).pdf

Lee, T. (2013). Fan activities from P2P file sharing to fansubs and fan fiction: Motivations, policy concerns, and recommendations. Texas Review of Entertainment \& Sports Law, 181-198. Retrieved from https://texashistory.unt.edu/ark:/67531/metapth654445/m2/1/high_res_d /UNT-0049-0042.pdf

Low, P. (2006). Song translation. In K. Brown (Ed.), Encyclopedia of Language \& Linguistics, ( $2^{\text {nd }}$ ed.), Vol 2, (pp. 511-514). Amsterdam: Elsevier. Retrieved from https://www.scribd.com/doc/41356968/ Brown-Ed-Encyclopedia-of-Language-and-Linguistics-2

Luyken, G., Herbst, T., Langham-Brown, J., Reid, H., \& Spinhof, H. (1991). Overcoming: Language Barriers in Television: Dubbing and Subtitling for the European Audience. Dusseldorf: The European Institute for the Media.

Matkivska, N. (2014). Audiovisual translation: Conception, types, characters' speech and translation strategies applied. Studies About Languages, (25), 38-44. Retrieved from http://kalbos.ktu.lt/ index.php/KStud/article/viewFile/8516/4304

Newmark, P. (1981). A Text Book of Translation. Oxford, Pergamon Press.

Nida, E. A. (1964). Toward a Science of Translating. Leiden, EJ. Brill.

Nornes, A. M. (1999). For an abusive subtitling. Film Quarterly, 52(3), 17-34. Retrieved from http://www.sub2learn.ie/downloads/ nornes_abusive_subtitling.pdf

O'Hagan, M. (2009). Evolution of user-generated translation: Fansubs, translation hacking and crowdsourcing. School of Applied Language and Intercultural Studies, Dublin City University, 49-121. Retrieved from https://www.academia.edu/4462788/Evolution_of_Usergenerated Translation Fansubs Translation_Hacking and Crowdsourc ing

Orrego-Carmona, D. (2014). Where is the audience? Testing the audience reception of non-professional subtitling. Translation Research Projects 5, 77-92. Retrieved from https://www.researchgate.net/ publication/268485198 Where is the audience Testing the audience reception_of_non-professional_subtitling 
Pedersen, J. (2005). How is culture rendered in subtitles? MuTra, Challenges of Multidimensional Translation: Conference Proceedings, 1-18. Retrieved from http://www.euroconferences. info/proceedings/2005_Proceedings/2005_Pedersen_Jan.pdf

Pérez-González, L. (2009). Audiovisual translation. In M. Baker, and G. Saldanha (Eds.), Routledge Encyclopedia of Translation Studies. $\left(2^{\text {nd }}\right.$ ed.), (pp.13-20). London: Routledge.

Pérez-González, L. (2014). Audiovisual Translation: Theories, Methods and Issues. Routledge: London.

Shuttleworth, M., \& Cowie, M. (1997). Dictionary of Translation Studies. Manchester, St Jerome Publishing.

Thawabteh, M., \& Musallam, S. (2016). Addressing coherence in EnglishArabic subtitling by amateur aficionados. Komunikacija I Kultura online, $\quad \operatorname{VII}(7), \quad$ 109-127. $\quad$ Retrieved from http://www.komunikacijaikultura.org/KK7/KK7Thawabtheh.pdf

Tian, Y. (2011). Fansubs cyber culture in China (master's thesis). Georgetown University. Retrieved from: https://repository.library. georgetown.edu/handle/10822/552957.

Trēde, E. (2016). Fansubbing in Latvia and its comparison to audio visual translations produced by translation (master's thesis). Latvijas Universitate. Retrieved from: https://www.academia.edu/32111509/ Fansubbing_in_Latvia_and_its_Comparison_to_Audio_Visual_Translat ions.pdf.

Tveit, J. (2009). Dubbing versus subtitling: Old battleground revisited. In DíazCintas J. \& Anderman G. (Eds.), Audiovisual Translation: Language Transfer on Screen, (pp. 85-96). London: Macmillan.

Venuti, L. (1995). The Translator's Invisibility: A History of Translation. London, Routledge.

Vinary, J., \& Darbelnet, J. (2000). A Methodology for translation. In Venuti. L. The Translation Studies, Reader, (pp. 84-93). London, Routledge.

Wongseree, T. (2016). Creativity in Thai fansubbing: A Creative translation practice as perceived by fan audiences of the Korean variety show Running Man. Centre for Translation and Intercultural Studies CTIS Occasional Papers, 7, 60-86. Retrieved from http://hummedia. manchester.ac.uk/schools/salc/centres/ctis/publications/occasionalpapers/Wongseree.pdf

Yang, W. (2010). Brief study on domestication and foreignization in translation. Journal of Language Teaching and Research, 1(1), 77-80. Retrieved from http://citeseerx.ist.psu.edu/viewdoc/download?doi $=10.1 .1 .472 .1452 \& \mathrm{rep}=$ rep1\&type $=$ pdf

Zojer, H. (2011). Cultural references in subtitles: A Measuring device for interculturality? Babel, 394-413. Retrieved from http://tranb300. ulb.ac.be/2012-2013/groupe212/archive/files/446dc0acd2418a517cf 4f9803cddf7cc.pdf 